LBNL-55340 Pt. 2

\title{
Distributed Energy Resources at Naval Base Ventura County Building 1512: A Sensitivity Analysis
}

\author{
Prepared for the \\ Federal Energy Management Program \\ Assistant Secretary for Energy Efficiency and Renewable Energy \\ U.S. Department of Energy \\ Principal Authors \\ Owen C Bailey and Chris Marnay \\ Ernest Orlando Lawrence Berkeley National Laboratory \\ 1 Cyclotron Road, MS 90R4000 \\ Berkeley CA 94720-8136
}

June 2005

This work described in this paper was funded by the Assistant Secretary of Energy Efficiency and Renewable Energy, through the Federal Energy Management Program, of the U.S. Department of Energy under Contract No. DE-AC03-76SF00098. 



\section{Acknowledgments}

The work described in this report was funded by the Assistant Secretary of Energy Efficiency and Renewable Energy, through the Federal Energy Management Program, of the U.S. Department of Energy under Contract No. DE-AC03-76SF00098.

The California Energy Commission also provided prior funding to develop and validate the DERCAM model that was used for this analysis.

We would like to thank the personnel at Naval Base Ventura County who provided considerable assistance by gathering information and by hosting our team at the site, including Tom Santoianni, Bob Demyanovich, Deborah Stewart, and Chris Karandang. Also, thanks to the team from AEPC Group, LLC for coordinating the initial site visit and for their energy audit with Berkeley Lab.

Steve Greenberg and Andy Green from LBNL also helped organize the initial site visit and energy audit, provided background information on NBVC, and answered questions about energy infrastructure at the site. 



\section{Table of Contents}

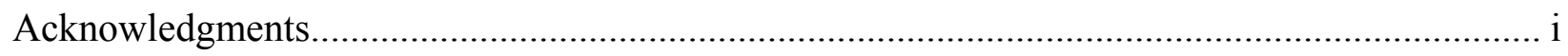

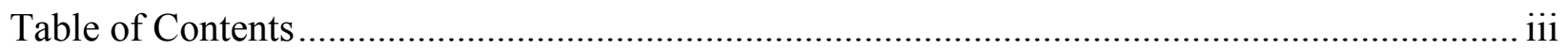

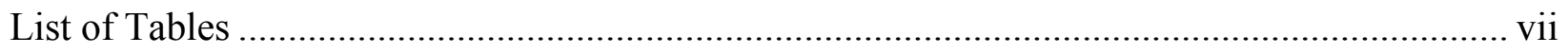

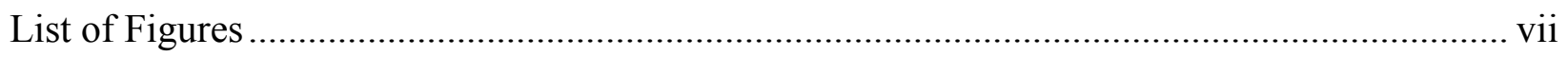

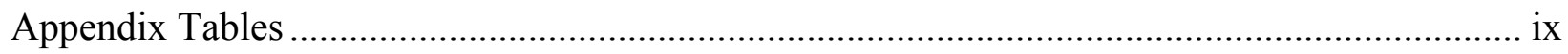

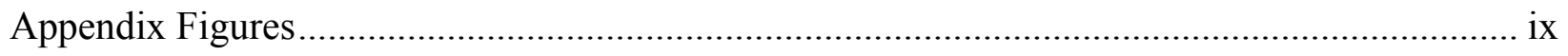

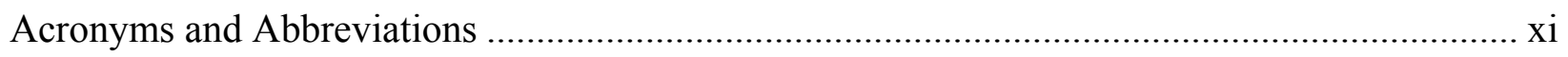

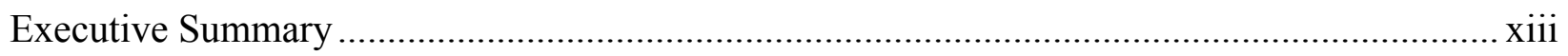

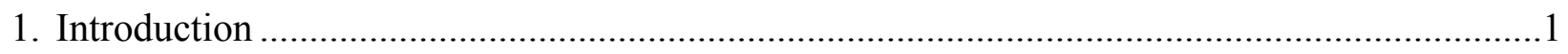

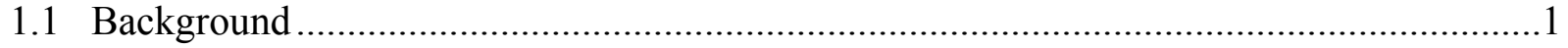

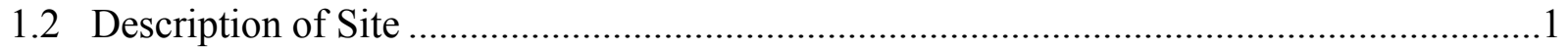

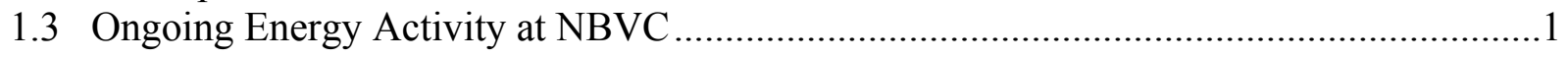

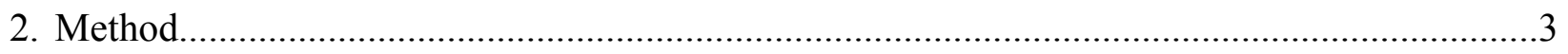

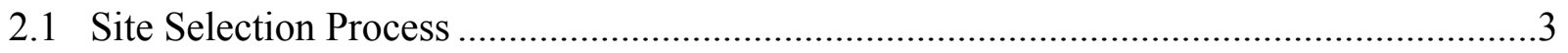

2.2 DER-CAM overview …………………………....................................................

2.3 Model Characteristics: separate and integrated refrigeration ...........................................

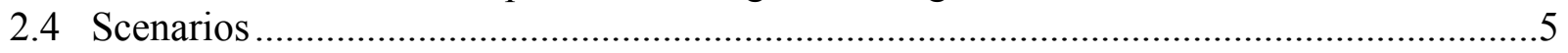

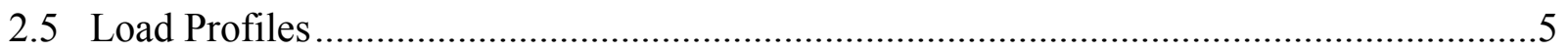

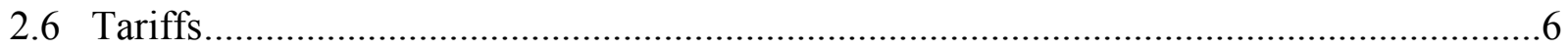

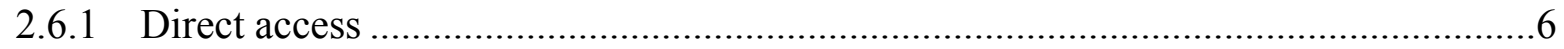

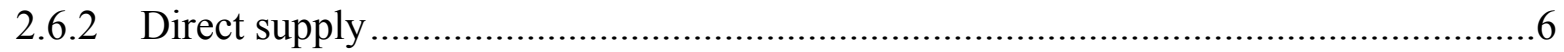

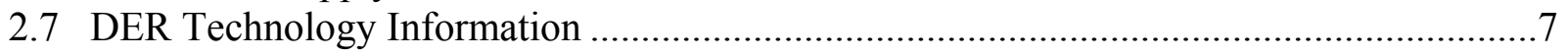

2.8 Absorption Refrigeration .....................................................................................

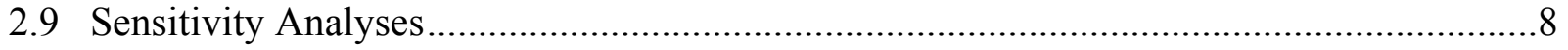

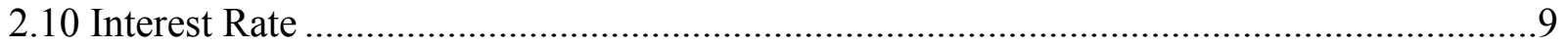

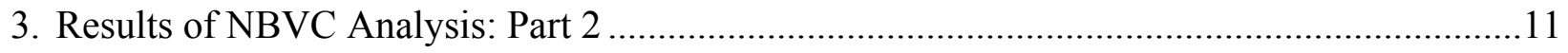

3.1 Separate Refrigeration Load Model...............................................................................11

3.2 Results: Integrated Refrigeration Load Model ……….....................................................13

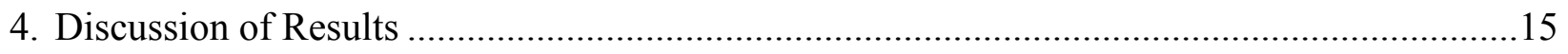

4.1 Scenario 1 Results: No DER Installation, Separate Refrigeration Load ............................15

4.2 Scenario 2 Results: Installation of DER, Separate Refrigeration Load ..............................15

4.3 Scenario 1 Results: No DER Installation, Integrated Refrigeration Load ...........................16 
4.4 Scenario 2 Results: Installation of DER, Integrated Refrigeration Load...........................16

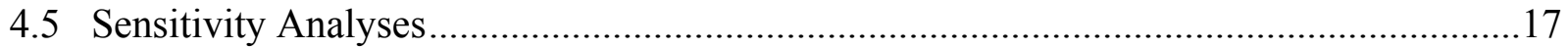

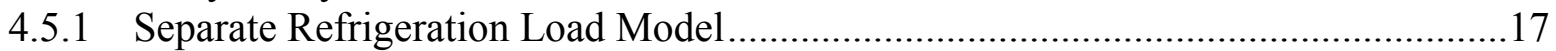

4.5.2 Integrated Refrigeration Load Model ………....................................................22

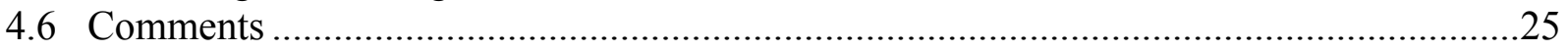

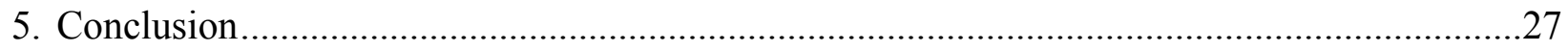

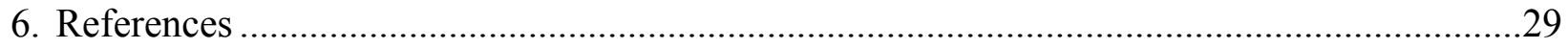

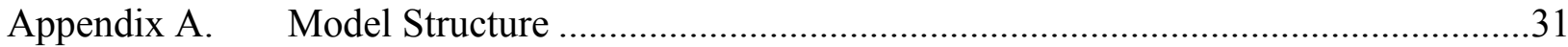

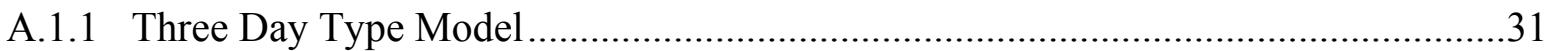

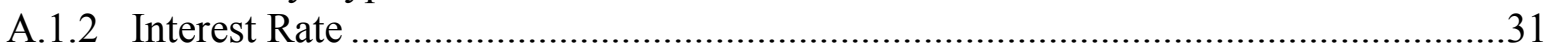

A.1.3 Parameter Inputs to DOE-2 2..........................................................................

Appendix B. Assumptions in Modeling Process...................................................................33

B.1.1 Assumptions Made for Modeling Building 1512 at NBVC ....................................33

B.1.2 Assumptions Made for Efficiency Calculations ..........................................................34

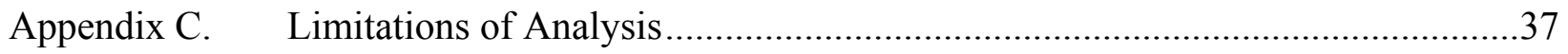

Appendix D. Technology Performance and Price Information...............................................39

D.1 Technology Performance and Price Parameters …………..................................................39

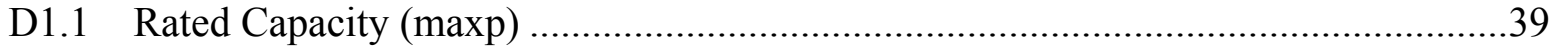

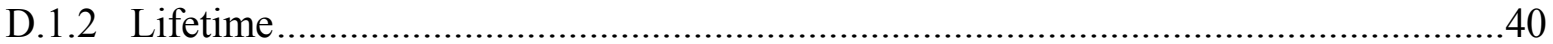

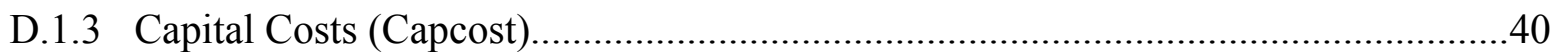

D.1.4 Operation and Maintenance Fixed Costs (OMFix) ................................................40

D.1.5 Operation and Maintenance Variable Costs (OMVar) ……......................................40

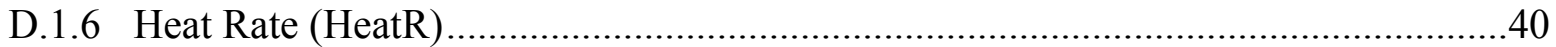

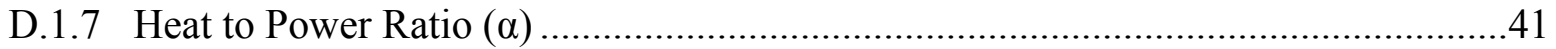

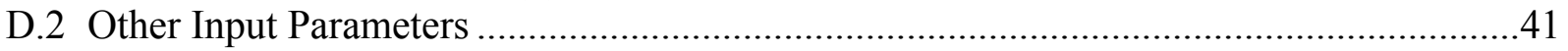

D.2.1 DER-CAM parameters.........................................................................................

D.2.2 Conversion Efficiency for Recoverable Heat to Load Displacement $(\gamma)$..................4 41

D.2.3 Conversion Efficiency for Recoverable Heat to Refrigeration Load Displacement $(\gamma) 42$

D.2.4 Conversion Efficiency for Fuel to Load Displacement $(\beta)$.......................................43

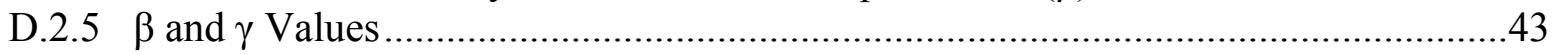

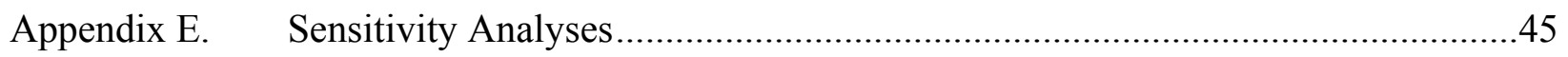

E.1 Parameters in the Core Model....................................................................................45

E.1.1 Sensitivity Analysis Range of Parameters ..............................................................45

Appendix F. CPUC Self-generation Incentive Program ………………………...................47

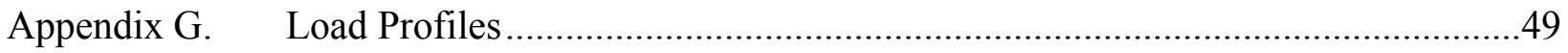

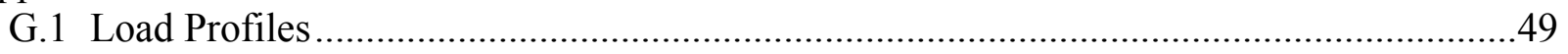

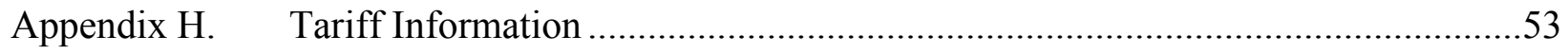

H.1 Summary of NBVC Tariff ......................................................................................5 
Distributed Energy Resources at Naval Base Ventura Country Building 1512

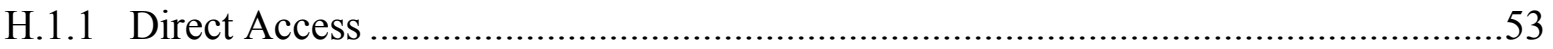

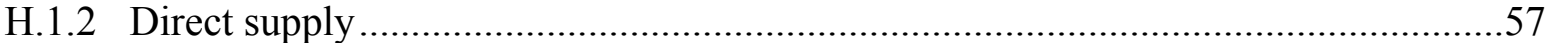





\section{List of Tables}

Table 1: Description of Scenarios Analyzed at NBVC

Table 2: Building 1512 Annual Energy Consumption and Production Results - Separate

Refrigeration Load 11

Table 3: Building 1512 Annual Energy Cost Results - Separate Refrigeration Load. .... 11

Table 4: Building 1512 Annual Energy Consumption and Production Results - Integrated Refrigeration Load 13

Table 5: Building 1512 Annual Energy Cost Results - Integrated Refrigeration Load 13

\section{List of Figures}

Figure 1: DER-CAM Schematic

Figure 2: Summary of Results for No DER and DER installation - Separate Refrigeration Load

Figure 3: Summary of Results for No DER and DER installation - Integrated Refrigeration Load

Figure 4: Capital and O\&M Costs Sensitivity - Separate Refrigeration Load............................. 18

Figure 5: Electricity and Demand Price Sensitivity - Separate Refrigeration Load ..................... 19

Figure 6: Natural Gas and Spark Spread Sensitivity - Separate Refrigeration Load .................... 20

Figure 7: Standby Charge Sensitivity - Separate Refrigeration Load .......................................... 21

Figure 8: Capital and O\&M Costs Sensitivity Analysis - Integrated Refrigeration Load ............ 22

Figure 9: Electricity and Demand Price Sensitivity - Integrated Refrigeration Load .................... 23

Figure 10: Spark-Spread Ratio Sensitivity Analysis - Integrated Refrigeration Load.................. 24

Figure 11: Standby Charge Sensitivity Analysis - Integrated Refrigeration Load ....................... 25 



\section{Appendix Tables}

Table A- 1: Area of each Section of Building 1512 ................................................................ 31

Table A- 2: DER-CAM Technology Cost and Performance Information.................................. 39

Table A- 3: Underlying Assumptions Used For $\beta$ and $\gamma$ Values .......................................... 44

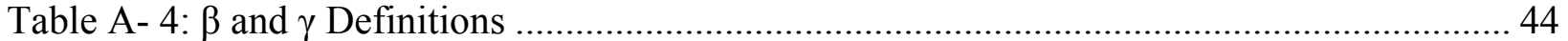

Table A- 5: Technologies Eligible for CPUC Self-Generation Rebates.................................. 47

Table A- 6: Direct Access Tariff Components at NBVC .................................................... 54

Table A- 7: SCE Schedule TOU-8, applicable for direct access and SCE TOU-8 tariffs ........... 56

\section{Appendix Figures}

Figure A- 1: Electric Only Load Profile for Building 1512 .............................................. 51

Figure A- 2: Space Heating Only Load Profile for Building 1512 ......................................... 51

Figure A- 3: Cooling Only Load Profiles for Building 1512 .............................................. 52

Figure A- 4: Direct Access Energy Supply Prices by Strategic Energy .................................. 54

Figure A- 5: NBVC Natural Gas Commodity Prices 2002-2003 .......................................... 57 



\section{Acronyms and Abbreviations}

$\begin{array}{ll}\text { Abs } & \text { absorption cooling } \\ \text { CBC } & \text { Construction Battalion Center } \\ \text { CHP } & \text { combined heat and power } \\ \text { COP } & \text { coefficient of performance } \\ \text { CPUC } & \text { California Public Utilities Commission } \\ \text { DA } & \text { direct access } \\ \text { DA-CRS } & \text { direct access cost responsibility surcharge } \\ \text { DER-CAM } & \text { Distributed Energy Resources Customer Adoption Model } \\ \text { DG } & \text { distributed generation } \\ \text { DOE-2 } & \text { building energy simulation software developed by Berkeley Lab } \\ \text { DWR } & \text { Department of Water Resources } \\ \text { ESP } & \text { energy service provider } \\ \text { FEMP } & \text { Federal Energy Management Program } \\ \text { FERC } & \text { Federal Energy Regulatory Commission } \\ \text { GJ } & \text { gigajoule } \\ \text { HPC } & \text { historic procurement charge } \\ \text { kWh } & \text { kilowatt hour } \\ \text { MBTU } & \text { million BTU } \\ \text { MWh } & \text { megawatt hour } \\ \text { NAS } & \text { Naval Air Station } \\ \text { NBVC } & \text { The Naval Base Ventura County } \\ \text { NEX } & \text { Navy Exchange } \\ \text { NG } & \text { natural gas } \\ \text { NPV } & \text { net present value } \\ \text { NREL } & \text { National Renewable Energy Laboratory } \\ \text { O\&M } & \text { operation and maintenance } \\ \text { PV } & \text { photovoltaic } \\ \text { SCE } & \text { Southern California Edison } \\ \text { SoCalGas } & \text { Southern California Gas Company } \\ \text { t/a } & \text { metric tons per year } \\ \text { TeChars } & \text { Technology Characterizations Report } \\ \text { TOU-8 } & \text { SCE time of use tariff number } 8 \\ \text { UPS } & \text { uninterruptible power supply } \\ \text { URG } & \text { utility retained generation } \\ & \end{array}$





\section{Executive Summary}

This report is the second of a two-part study by Berkeley Lab of a DER (distributed energy resources) system at Navy Base Ventura County (NBVC). First, a preliminary assessment of the cost effectiveness of distributed energy resources at Naval Base Ventura County (NBVC) Building 1512 was conducted in response to the base's request for design assistance to the Federal Energy Management Program (Bailey and Marnay, 2004). That report contains a detailed description of the site and the DER-CAM (Consumer Adoption Model) parameters used. This second report contains sensitivity analyses of key parameters in the DER system model of Building 1512 at NBVC and additionally considers the potential for absorption-powered refrigeration.

The prior analysis found that under the current tariffs, and given assumptions about the performance and structure of building energy loads and available generating technology characteristics, installing a $600 \mathrm{~kW}$ DER system with absorption cooling and recovery heat capabilities could deliver cost savings of about $14 \%$, worth $\$ 55,000$ per year. However, under current conditions, this study also suggested that significant savings could be obtained if Building 1512 changed from its current direct access contract to a SCE TOU-8 (Southern California Edison time of use tariff number 8) rate without installing a DER system. Evaluated on this tariff, the potential savings from installation of a DER system would be about $4 \%$ of the total bill, or $\$ 16,000$ per year.

This second report determines the potential DER energy savings and the robustness of such a system by revealing the critical points of various parameters and their effects on the system's design and cost effectiveness. Because energy consumption in Building 1512 is so high, the impact of changing electricity costs and tariff structure is investigated in depth. This study also considers many of the model's other parameters, including technology turnkey and O\&M (operation and maintenance) costs, technology lifetime, electricity and demand tariffs, standby charges, cost of capital (real interest rate), and natural gas prices using sensitivity analysis.

The existence of thermal loads to take advantage of residual heat is an important factor determining efficiency and cost effectiveness; therefore, sensitivity analyses were performed on two separate models of Building 1512: a model in which the refrigeration loads are part of the site's electricity-only load (referred to as the integrated refrigeration model), and a model including refrigeration loads as a separate end use that can be served with absorption cooling (referred to as the separate refrigeration model). In the previous report on Building 1512, the refrigeration loads were integrated with the electricity-only load. Building energy use profiles were estimated using monthly bill data and DOE-2 simulation.

The DER-CAM optimal solution for the separate refrigeration load model is installation of two $300 \mathrm{~kW}$ natural gas engines with absorption cooling and heating capabilities. Under a legacy direct access tariff, installing a DER system will reduce energy costs by $\$ 95,000$ per year, a $22 \%$ savings with a six-year payback, while more than doubling the site's overall energy efficiency from $35 \%$ to $77 \%$. ${ }^{1}$ This DER system would also reduce carbon emissions by $188 \mathrm{t} / \mathrm{a}(28 \%)$ and

\footnotetext{
${ }^{1}$ Energy efficiency is defined as the ratio of all end-use energy consumption to all primary energy inputs for the DER system and utility sources.
} 
shift Building 1512's energy purchases from nearly all electric to nearly all natural gas. This result proves fairly robust since the optimal solution remains the same if the technology costs increase by $20 \%$, natural gas prices increase by $20 \%$, or standby charges increase to $\$ 2 / \mathrm{kW} /$ month. Beyond those critical points the model generally decreases recommended capacity to $300-400 \mathrm{~kW}$ of natural gas engines. Absorption cooling is a technology that takes residual heat and converts it to a chilled fluid for space cooling or refrigeration. Recent model results indicate that absorption refrigeration is a valuable thermal load to serve with residual heat because it is a sizable, steady, and year round.

The integrated refrigeration model is similar to the one analyzed in the previous study. Refrigeration loads are part of the electricity-only loads and cannot be served with absorption cooling. The optimal DER solution under this scenario calls for installing one $500 \mathrm{~kW}$ natural gas engine with absorption cooling and heating capabilities. This option results in a reduction of annual energy costs by $\$ 50,000$ per year, a $12 \%$ savings with a six and a half year payback. The site's energy efficiency improves from $35 \%$ to $60 \%$ and carbon emissions are reduced by 122 t/a, or $20 \%$. This DER system configuration remains cost effective if electricity prices increase in the future, standby rates remain below $\$ 5 / \mathrm{kW}$, and cost of capital is $10 \%$ real or less.

If the main concerns are DER system cost overruns, installing one $300 \mathrm{~kW}$ natural gas engine with absorption cooling and heating capabilities provides a more conservative choice. The 300 $\mathrm{kW}$ natural gas engine is also recommended if standby rates are predicted to remain below $\$ 10 / \mathrm{kW} /$ month or natural gas prices are expected to increase in real terms by $20 \%$ or more.

This analysis shows financial, energy, and environmental savings may be obtained by installing a DER system at the site. The additional ability to use residual heat, especially to displace expensive electric driven cooling systems for space cooling and refrigeration, improves the overall economic picture from a modest savings of $\$ 50,000$ per year $(14 \%)$ to a more compelling $\$ 95,000$ per year, a $22 \%$ reduction. Therefore, the technical and financial feasibility of an absorption refrigeration system at Building 1512 is crucial to evaluating DER system installation at the site. Reliability and power quality improvements for critical loads in Building 1512 may be other drivers for a DER system installation.

As noted in the previous study, on-site power generation could shift the building's energy source from almost all electricity, as it is now, to mostly natural gas for on-site generation. A rate structure or commodity price change could easily increase the energy bill by $\$ 50,000$ a year, roughly the difference in annual energy costs between Building 1512's electricity bill on its current direct access contract versus the DER installation scenario. This is also the magnitude of savings between the annual energy costs of Building 1512's electricity bill on its current direct access contract versus the default SCE TOU- 8 rate. Therefore, the influence of electricity and natural gas tariff rates and contracts at NBVC should be studied carefully in the process of evaluating potential cost savings and efficiency improvements. The timing of end-use energy efficiency savings and energy consumption are also highly influential in the overall energy costs and the financial value of a DER system.

Currently no interval data are available on power or heat demand at Building 1512. Energy consumption (kWh and therms) data are collected only on a monthly basis, but power demands 
$(\mathrm{kW})$ are not tracked. The current direct access tariff uses the same energy rate for each time period so demand charges do not appear to contribute greatly to energy bills. However, more detailed and more frequently monitored electricity data, such as would be available from interval meters, could provide useful information on energy consumption patterns, guide decisions for energy efficiency and demand response programs, and assist in evaluation of on-site generation options. Faster acquisition of utility consumption data could also help identify and quickly correct problems with the building's energy systems before they affect utility bills, customer comfort, or the grocery inventory. 



\section{Introduction}

\subsection{Background}

This report contains sensitivity analyses of the cost effectiveness and technology selection of distributed energy resources (DER) at Naval Base Ventura County (NBVC) Building 1512, and has been prepared in response to a request by NBVC for design assistance to the Federal Energy Management Program (FEMP).

NBVC is comprised of two nearby bases located $100 \mathrm{~km}$ (60 miles) northwest of Los Angeles: the Naval Air Station (NAS) at Point Mugu and the Construction Battalion Center (CBC) at Port Hueneme, founded in 1941 and 1942 respectively. Point Mugu has two runways for jet aircraft, while Port Hueneme offers a deep-water naval port. NBVC employs over 6,000 civilians, 9,000 military personnel and 1,300 contractor staff. In addition, NBVC hosts over 60 tenant commands.

Port Hueneme's Building 1512 was selected after a site visit because it uses the most electricity of any building on the two bases, presents opportunities for absorption space cooling and refrigeration, is relatively easy to access, and has other neighboring buildings with substantial thermal loads that may ultimately become part of a broader microgrid. A microturbine is being installed to help heat the swimming pool at Building 73.

\subsection{Description of Site}

Building 1512 is approximately 13,000 $\mathrm{m}^{2}\left(136,000 \mathrm{ft}^{2}\right)$ and houses a Navy Exchange, known as NEX (a large retail store), the Commissary (a large grocery store), and other smaller businesses, notably a food court. Building 1512 is the largest metered electricity consumer at either Port Hueneme or Point Mugu.

The Naval Base purchases electricity from Strategic Energy LLC, and retail and delivery services from Southern California Edison (SCE) under a legacy energy service provider (ESP) contract effective prior to September 2001. Natural gas is procured through the Defense Energy Support Center in Fort Belvoir, VA and delivered by Southern California Gas (SoCalGas). NBVC Public Works Department recharges base facilities at fixed prices for electricity, natural gas, and water based on metered consumption.

\subsection{Ongoing Energy Activity at NBVC}

Port Hueneme has several ongoing energy projects and demonstrations. A standby generator optimization review was performed by C\&H Engineering under subcontract to SoCalGas. ${ }^{2}$ The Public Works building is powered by a $31 \mathrm{~kW}$ rooftop photo voltaic or PV system, which serves all power requirements for the building and acts as an uninterruptible power supply (UPS). ${ }^{3}$ On

\footnotetext{
${ }^{2}$ Naval Base Ventura County Standby Generator Optimization Review, Southern California Gas Company, August 2001.

${ }^{3}$ Tom Santoianni, personal communication.
} 
sunny days, the PV supplies extra power to the base's electricity network. ${ }^{4}$ There are also four solar thermal collectors supplying the building's hot water requirements.

\footnotetext{
${ }^{4}$ Tom Santoianni, email communication, 25 March 2004.
} 


\section{Method}

\subsection{Site Selection Process}

After a site visit, Building 1512 was selected because it presents the largest electrical load on the two bases, offers interesting opportunities for absorption cooling, and has neighboring buildings that may together become a microgrid. The building is approximately $13,000 \mathrm{~m}^{2}\left(136,000 \mathrm{ft}^{2}\right)$ and in FY (fiscal year) 2003, consumed 2,904 MWh of electricity and 1,239 GJ (1,174 MBTU) of natural gas. ${ }^{5}$ The peak electrical load is estimated to be around 1,200 kW for the integrated refrigeration load model and $910 \mathrm{~kW}$ in the separate refrigeration load model. The presence of both a retail store and a supermarket make Building 1512 a central point of life for personnel at the base. Several surrounding buildings (e.g., a gas station, a McDonald's, a laundromat, a bowling alley, a large outdoor pool with locker rooms, and a gymnasium) also have energy loads potentially interesting for future microgrid analyses.

\subsection{DER-CAM overview}

The analysis of Building 1512 was done in part using the Distributed Energy Resources Customer Adoption Model (DER-CAM), which finds the optimal combination of installed equipment and an idealized operating schedule to minimize the site's energy bills, given the performance and cost data on available DER technologies, utility tariffs, and site electrical and thermal loads over an historic test period.

DER-CAM is a mixed integer program formulated in GAMS $^{6}$ (General Algebraic Modeling System). The objective function to be minimized is the annual cost of providing energy services to the site, through either utility electricity and gas purchases or DER operation (or a combination of both) in total dollars for a test year, typically a recent historic year. The objective function estimates the annual costs of electricity purchases, gas purchases (for both generating fuel and direct use), operation and maintenance (O\&M) costs, and the annualized capital costs of DER equipment.

DER-CAM has recently been extended to include absorption refrigeration ability, both in terms of the technology to supply absorption refrigeration and the end-use refrigeration loads. This is described in more detail in Appendix D and Appendix G. In this model, energy use is divided into six end uses: electricity-only, cooling, refrigeration, space heating, water heating, and natural-gas-only. The program's output is an idealized set of DER technologies to install (if any) and their hourly operating schedules, as well as utility electricity and natural gas purchases, all selected to minimize the annual costs of meeting energy demand for the site over the test year.

A key constraint is that energy demand for each hour must be met either by the purchase of energy from utilities, operation of a technology or set of technologies selected by the model, or a combination of these options. In addition, all environmental rules must be obeyed, and technical equipment capabilities cannot be exceeded.

\footnotetext{
${ }^{5}$ NBVC Public Works. "Top Utility Consumers for FY 03.” Received December 2003.

${ }^{6}$ GAMS is a proprietary software product used for high-level modeling of mathematical programming problems. It is owned by the GAMS Development Corporation (http://www.gams.com) and is licensed to Berkeley Lab.
} 
Another key performance constraint is that any installed DER technologies must be operated at $50 \%$ or more of their nameplate capacity or they will be shut down. This constraint ensures that the generators function in their most efficient power range and that multiple generators are installed to meet fluctuating energy loads. This does not apply to photovoltaics (PV).

The model's inputs and outputs are depicted graphically in Figure 1 below

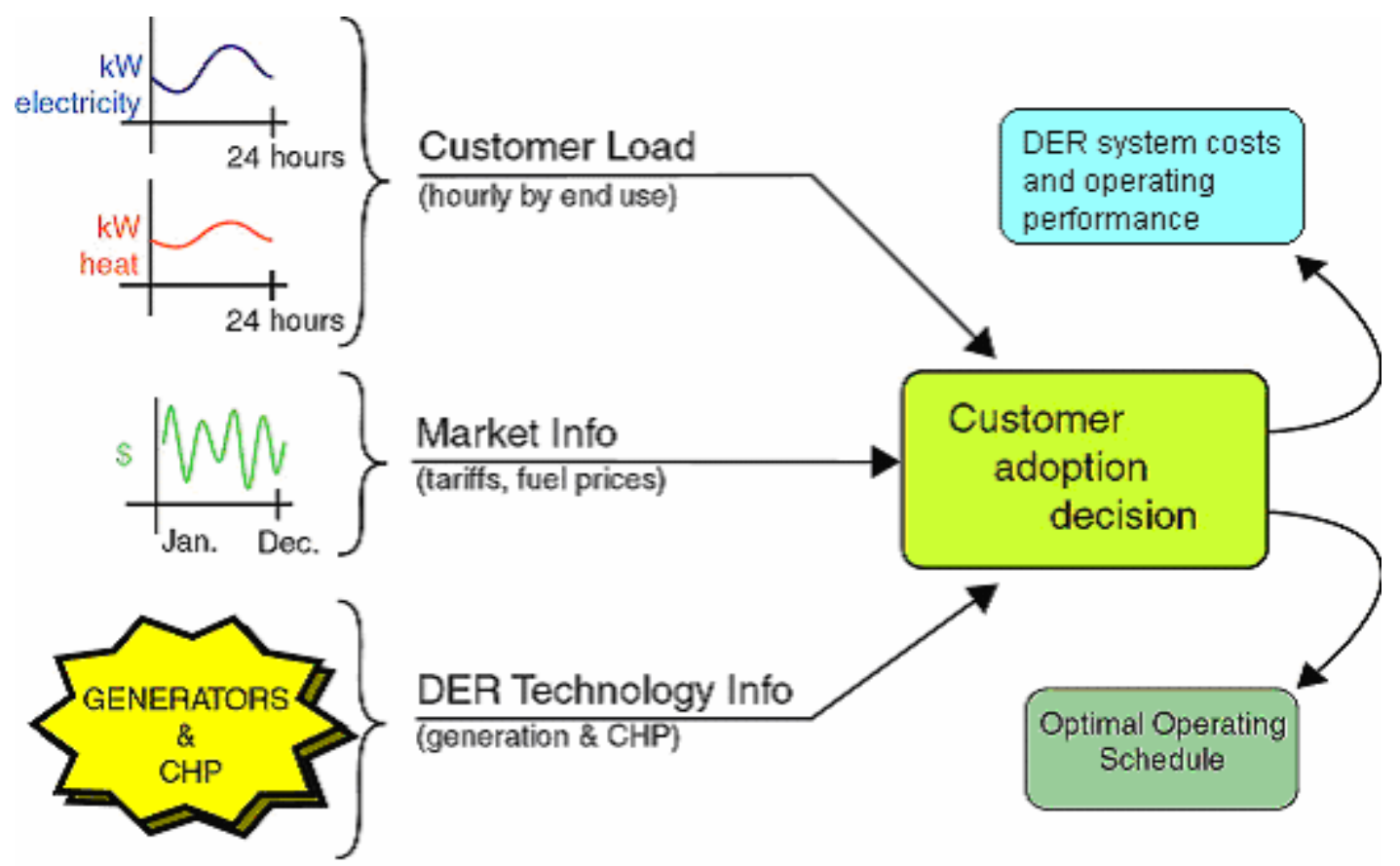

Figure 1: DER-CAM Schematic

DER-CAM results are not intended to be fully documented proposals for DER systems. Rather they provide insight into which general technologies and system configurations should be analyzed further. DER-CAM's optimal system results can offer an excellent starting point for more in-depth study. It is much more efficient than evaluating candidate systems one at a time.

\subsection{Model Characteristics: separate and integrated refrigeration}

Sensitivity analyses were performed on two separate models of Building 1512: a model including refrigeration loads as a separate end use to be served with absorption cooling (the separate refrigeration model) and one in which the refrigeration loads are part of the site's electricity-only load (the integrated refrigeration model). It is important to study both models because thermal loads influence the DER system's efficiency and cost effectiveness. In the previous report on Building 1512, the refrigeration loads were integrated with the electricity-only load. Building energy use profiles were estimated using monthly bill data and DOE-2 simulation. 


\subsection{Scenarios}

To explore the options available for DER installation, two scenarios were modeled, each presenting useful information for determining the financial benefits of different DER system designs (see Table 1). The "no DER installation" scenario provides the baseline for identifying any financial benefits from DER systems, and the "installation of DER" scenario presents the optimized combination of DER technologies and operating schedules to maximize savings. Results for each scenario were obtained for both separate refrigeration load and integrated refrigeration load models.

Table 1: Description of Scenarios Analyzed at NBVC

\begin{tabular}{|l|l|l|}
\hline Scenario & Electricity Tariff & Natural Gas Tariff \\
\hline $\begin{array}{l}\text { Scenario 1 } \\
\text { No DER installation }\end{array}$ & $\begin{array}{l}\text { direct access: } \\
\text { current legacy contract }\end{array}$ & direct access \\
\hline $\begin{array}{l}\text { Scenario 2 } \\
\begin{array}{l}\text { Installation of DER } \\
\text { Any technology and capacity } \\
\text { combination allowed (true } \\
\text { optimization) }\end{array}\end{array}$ & direct access & direct access \\
\hline
\end{tabular}

\subsection{Load Profiles}

Ideally, complete electric and thermal load profiles on an hourly basis for a full year (historical, or even better, forecast) would be available as input to DER-CAM. At NBVC, however, hourly and peak load data and load shape information were not available. Deborah Stewart, Public Utilities Specialist, provided a spreadsheet listing the monthly meter readings for both the Commissary and the NEX for the five years from November 1998 to January 2004 and showing energy consumption since the last meter reading in MWh and MBTU. These monthly electric and natural gas meter data were averaged to obtain baseline monthly electric and natural gas consumption.

The DOE-2 building energy simulator was used to estimate the missing data on hourly electricity, heating, and cooling loads. The following building types were used to approximate Building 1512: a retail store (NEX), a supermarket (Commissary), and a fast food restaurant (the food court).

The six DER-CAM load types used in this study are:

- electricity-only: loads such as lighting and computing met only by electricity that cannot be met by natural gas or CHP (combined heat and power),

- space cooling: loads met by electricity or heat recovery through absorption cooling,

- refrigeration: loads met by electricity or heat recovery through absorption cooling,

- space heating: loads met either directly by natural gas or with residual heat from CHP,

- water heating: loads met either directly by natural gas or with residual heat from CHP, 
- natural-gas-only: loads met only by natural gas and not CHP opportunities (primarily cooking).

The results were added to find the loads for each major component of Building 1512 and then adjusted to match the historic metered data (from November 1998 to January 2004). Two separate load profiles were developed for the two models of Building 1512: a model including refrigeration loads as a separate end use that can be served with absorption cooling (referred to as the separate refrigeration model) and a model where the refrigeration loads are part of the site's electricity-only load (referred to as the integrated refrigeration model).

For the separate refrigeration model, a flat refrigeration load was created by breaking out a portion of the electricity-only load. This process is described in detail in Appendix G. The electricity-only load from DOE- 2 was multiplied by 0.8 and cooling load was multiplied by 0.5 in order to match these loads, in addition to the refrigeration load, with the monthly billing data. The test site load profiles described in this report are presented in Appendix G.

For the integrated refrigeration model, the electricity-only and cooling loads from DOE-2 were multiplied by 0.96 to approximate the average electricity consumption loads provided by historic meter readings. The space heating, water heating, and natural-gas-only loads from DOE-2 were multiplied by 0.85 to match historic natural gas usage.

\subsection{Tariffs}

The previous study of Building 1512 evaluated three different tariff structures. This report focuses on the direct access tariff because that is what NBVC currently pays on and what they use for evaluating energy supply and demand investments.

\subsubsection{Direct access}

NBVC has a direct access contract with an energy service provider, Strategic Energy, and electricity delivery services through SCE under tariff TOU-8 Direct Access. The Strategic Energy contract is effective through March 2005 and is renewable indefinitely. ${ }^{7}$ Natural gas is also purchased from a direct supplier and SoCalGas charges for delivery. The net tariff estimated by combining the Strategic Energy charge and the SCE TOU-8 direct access charge is here called the "direct access" tariff.

\subsubsection{Direct supply}

Natural gas is obtained through the Defense Energy Support Center in Fort Belvoir, VA. Prices during the period from September 2002 to August 2003 fluctuated between \$3.16/GJ (\$3.330/MBTU) and \$6.63/GJ (\$6.99/MBTU), so an average price of \$5.11/GJ (\$5.39/MBTU) was used. SoCalGas delivers the gas and their delivery rate also varies monthly, so it was set at $\$ 0.95 / \mathrm{GJ}(\$ 1.00 / \mathrm{MBTU})$ based on the historic average. The total direct access gas rate totals $\$ 6.06 / \mathrm{GJ}(\$ 6.39 / \mathrm{MBTU})$.

\footnotetext{
${ }^{7}$ Veronica Jarvis, Strategic Energy, personal communication, March 2004.
} 


\subsection{DER Technology Information}

DER-CAM uses a technology database of the cost and performance information needed for modeling installation and operating options. The technologies include gas turbines, microturbines, natural gas engines, photovoltaics, and fuel cells. Data includes capital cost, fixed and variable operating costs, heat rate, and thermal energy production per $\mathrm{kWh}$. Each DER technology has three versions describing different CHP configurations with their resulting output: electricity only; electricity and heat; and electricity, heat, and cooling. To be consistent, DER technology capital costs and performance specifications are primarily taken from the Technology Characterization Report (TeChars) (Goldstein et al. 2003). The Distributed Energy Resources Customer Adoption Model Technology Data (Firestone 2004) also contains a detailed description of the data characteristics. The CPUC SelfGen (California Public Utilities Commission Self Generation) grants were included, reducing the capital cost of applicable technologies. A more detailed description of the technologies is presented in Appendix D. Table A- 2 in Appendix D describes the technology cost and performance information used in DER-CAM.

DER technologies (other than PV) are assumed to operate at $50 \%$ or more of their nameplate or maximum power rating, or they are shut down. This assumption ensures that the generator's heat rate and fuel efficiency are more realistic. Manufacturers specify these parameters at maximum power output, but efficiency tends to decline substantially at lower load levels, and many generators cannot run at low partial load.

The preliminary study of NBVC Building 1512 found that the inability to use all the residual heat at this site stems from the lack of heat loads in the building. The DER-CAM version used in the preliminary study did not include refrigeration end-use load among the options to consider. An attempt was made to develop estimates of the cooling load potential, gather additional cost and performance data on absorption chilling systems, and then include that information in the model. Details of this analysis are provided in Appendix D.2.3. This could be improved by a more detailed engineering study of the capacities and estimated performance of the refrigerator and freezer cooling systems in the building if NBVC is interested in absorption refrigeration.

\subsection{Absorption Refrigeration}

The absorption refrigeration component of this study is modeled after an absorption refrigeration system installed at a HEB supermarket in southwestern Texas by Richard Sweetser of Exergy Partners and Hugh Henderson of CDH Energy. ${ }^{8}$ The energy consumption of the refrigeration equipment was estimated from the data in a report by A.D. Little on commercial refrigeration (A.D. Little 2002). The derivations of the heat transfer parameters are described in detail in Appendix D.2.3. The system is based on a lithium bromide absorption chiller that produces a liquid refrigerant at $7^{\circ} \mathrm{C}\left(45^{\circ} \mathrm{F}\right)$ at the condensing coils. The goal is generate enough thermal energy for an absorption chiller to supply liquid refrigerant subcooling to the low temperature and medium temperature refrigeration racks. (Refrigeration racks are named for the temperature each compressor provides to the refrigerated area.) The absorption chiller assists the existing

\footnotetext{
${ }^{8}$ Richard Sweetser. "Use of Cooling, Heating, and Power in a Supermarket." Presentation at DOE/CETC Workshop on Microturbine Applications. January 20-22, 2004 and personal communication.
} 
HVAC system and four refrigeration units by providing liquid refrigerant subcooling at the aircooled condensing unit. Subcooling reduces the refrigerant temperature below the evaporating temperature at the condenser phase of the refrigerant cycle. The absorption chiller capacity is 70 $\mathrm{kW}$ (20 tons).

Absorption cooling in DER-CAM is accomplished by matching appropriately sized absorption chillers to generators with a corresponding increase in equipment cost. The cooling capacity of the system corresponds with the power capacity of the generating equipment.

\subsection{Sensitivity Analyses}

Sensitivity analyses on key parameters improve understanding of how the costs, benefits, and technology components of a DER system change as a result of changes to these parameters. Sensitivity analyses can help answer questions such as:

- What is the result if the DER system costs are more than expected?

- How much higher do DER system costs have to rise before the system becomes uneconomical?

- How might changes in natural gas and electricity prices affect the cost and installed capacity of an optimal DER system?

- How high do standby charges have to climb before DER becomes uneconomical?

Because energy consumption in Building 1512 is so high, changing electricity costs and tariff structure are of great concern. For this report, many parameters in both separate and integrated refrigeration models, including technology capital and O\&M costs together, technology lifetime, electricity $(\$ / \mathrm{kWh})$ and demand $(\$ / \mathrm{kW} /$ month) prices, standby charges, cost of capital (specifically real interest rate), and natural gas prices, were used in sensitivity analyses to determine the affect each has on annual energy cost, optimal system installation, and operation results. This report also determines a DER system's potential for energy savings and robustness by revealing the critical points for various parameters along with their impact on system design and cost effectiveness. For example, sensitivity analyses can find the points under scenario 2 where the optimal DER changes from a $500 \mathrm{~kW}$ natural gas engine to a $300 \mathrm{~kW}$ natural gas engine, or where DER is no longer cost effective.

Appendix E lists the specific parameters used in the analyses and the ranges of their variation. The core model is characterized by a standby charge of $\$ 0.44$ per $\mathrm{kW}$ per month, and a technology lifetime of 20 years for natural gas engines. The remaining numbers cited are multipliers of the original parameter levels, 0.9 and 1.1 are a 10\% decrease and increase respectively. The technology costs and tariff rates in the core model are described in Appendix $\mathrm{D}$ and Appendix $\mathrm{H}$ respectively. For the integrated refrigeration load analyses, the model included all natural gas engines less than or equal to $500 \mathrm{~kW}$, along with PV. Technologies that were unlikely to work well for this end use were eliminated from the possible choices. Each parameter was varied alone, holding others constant. Electricity prices and demand charges were varied together, along with DER system capital and O\&M fixed/variable costs. 
The existence of thermal loads for using the residual heat from a DER system is an important factor in its efficiency and cost effectiveness. Sensitivity analyses were performed on both the separate refrigeration model and the integrated refrigeration model.

\subsection{Interest Rate}

The interest rate is used to determine the annualized capital cost of the DER system over its lifetime. The separate refrigeration model uses a $5 \%$ interest rate. The integrated refrigeration model uses a $7.5 \%$ real interest rate as the standard rate for the sensitivity analysis and in the previous report and provides more conservative results. The $5 \%$ interest rate was thought to be more of a standard rate for DER-CAM analysis. The $7.5 \%$ interest rate was used to compare the integrated refrigeration model results with the previous study. The separate and integrated refrigeration load models are different enough that a slight difference in interest rates is not significant especially given the robustness of the results to interest rate changes. 



\section{Results of NBVC Analysis: Part 2}

The following tables present energy consumption and production and energy cost results for each of the scenarios. The graphs compare the results for each.

\subsection{Separate Refrigeration Load Model}

Annual energy balance results for each scenario are presented below in Table 2; the energy cost results appear in Table 3. Note that in Table 2, the values for absorption cooling and absorption refrigeration are the displaced electrical loads in MWh. The thermal loads are space and water heating loads met with residual heat from DER.

Table 2: Building 1512 Annual Energy Consumption and Production Results - Separate Refrigeration Load

\begin{tabular}{|c|c|c|c|c|c|c|c|c|c|c|c|}
\hline & 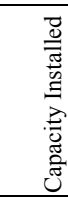 & 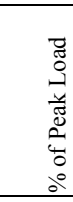 & Equipment & 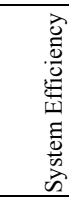 & \multicolumn{3}{|c|}{ Annual Utility Purchase } & \multicolumn{4}{|c|}{ Annual DER Production } \\
\hline & & & & & Electricity & $\begin{array}{c}\text { Gas for } \\
\text { DER }\end{array}$ & $\begin{array}{c}\text { Gas for } \\
\text { direct end } \\
\text { use }\end{array}$ & $\begin{array}{c}\text { Electricity } \\
\text { loads }\end{array}$ & Abs. Cool & $\begin{array}{c}\text { Abs } \\
\text { Refriger- } \\
\text { ation }\end{array}$ & $\begin{array}{c}\text { Thermal } \\
\text { loads }\end{array}$ \\
\hline & $(\mathrm{kW})$ & & & & $(\mathrm{MWh})$ & $(\mathrm{MWh})$ & (MWh) & (MWh) & $(\mathrm{MWh})$ & $(\mathrm{MWh})$ & (MWh) \\
\hline No DER & & & & $35 \%$ & 3,838 & 0 & 506 & 0 & 0 & 0 & 0 \\
\hline DER & 600 & $50 \%$ & $\begin{array}{l}2 \times 300 \mathrm{~kW} \text { NG } \\
\text { engine with } \\
\text { absorption chiller }\end{array}$ & $77 \%$ & 12 & 9,742 & 100 & 3,020 & 30 & 776 & 407 \\
\hline
\end{tabular}

Note: $1 \mathrm{MWh}=3,600 \mathrm{MJ}=34.13$ therms $=3,412,141 \mathrm{BTU}$

Table 3: Building 1512 Annual Energy Cost Results - Separate Refrigeration Load

\begin{tabular}{|c|c|c|c|c|c|c|c|c|c|c|c|c|}
\hline & 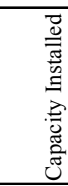 & Equipment & 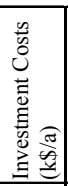 & 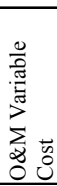 & Ann & al Utility & & & & & & \\
\hline & & & & & Electricity & $\begin{array}{c}\text { Gas for } \\
\text { DER }\end{array}$ & $\begin{array}{c}\text { Gas for } \\
\text { direct end } \\
\text { use }\end{array}$ & $\begin{array}{c}\text { Total } \\
\text { Energy } \\
\text { Costs }\end{array}$ & $\begin{array}{l}\text { Ave. } \\
\text { Elec. } \\
\text { Price }\end{array}$ & \begin{tabular}{|l} 
Bill Savings \\
Over No \\
DER Case \\
\end{tabular} & Payback & $\begin{array}{c}\text { Carbon } \\
\text { Emissions }\end{array}$ \\
\hline & $(\mathrm{kW})$ & & $(\mathrm{k} \$)$ & $(\mathrm{k} \$)$ & $(\mathrm{k} \$)$ & $(\mathrm{k} \$)$ & $(\mathrm{k} \$)$ & $(\mathrm{k} \$)$ & $\$ / k W h$ & $\begin{array}{l}(\%) \\
\end{array}$ & & $t / a$ \\
\hline No DER & & & 0 & 0 & 412 & 0 & 17 & 429 & 0.1073 & & & 664 \\
\hline DER & 600 & $\begin{array}{l}2 \times 300 \mathrm{~kW} \text { NG } \\
\text { engine with } \\
\text { absorption chiller }\end{array}$ & 60 & 51 & 5 & 212 & 6 & 334 & 0.0855 & $22 \%$ & 5.8 & 476 \\
\hline
\end{tabular}




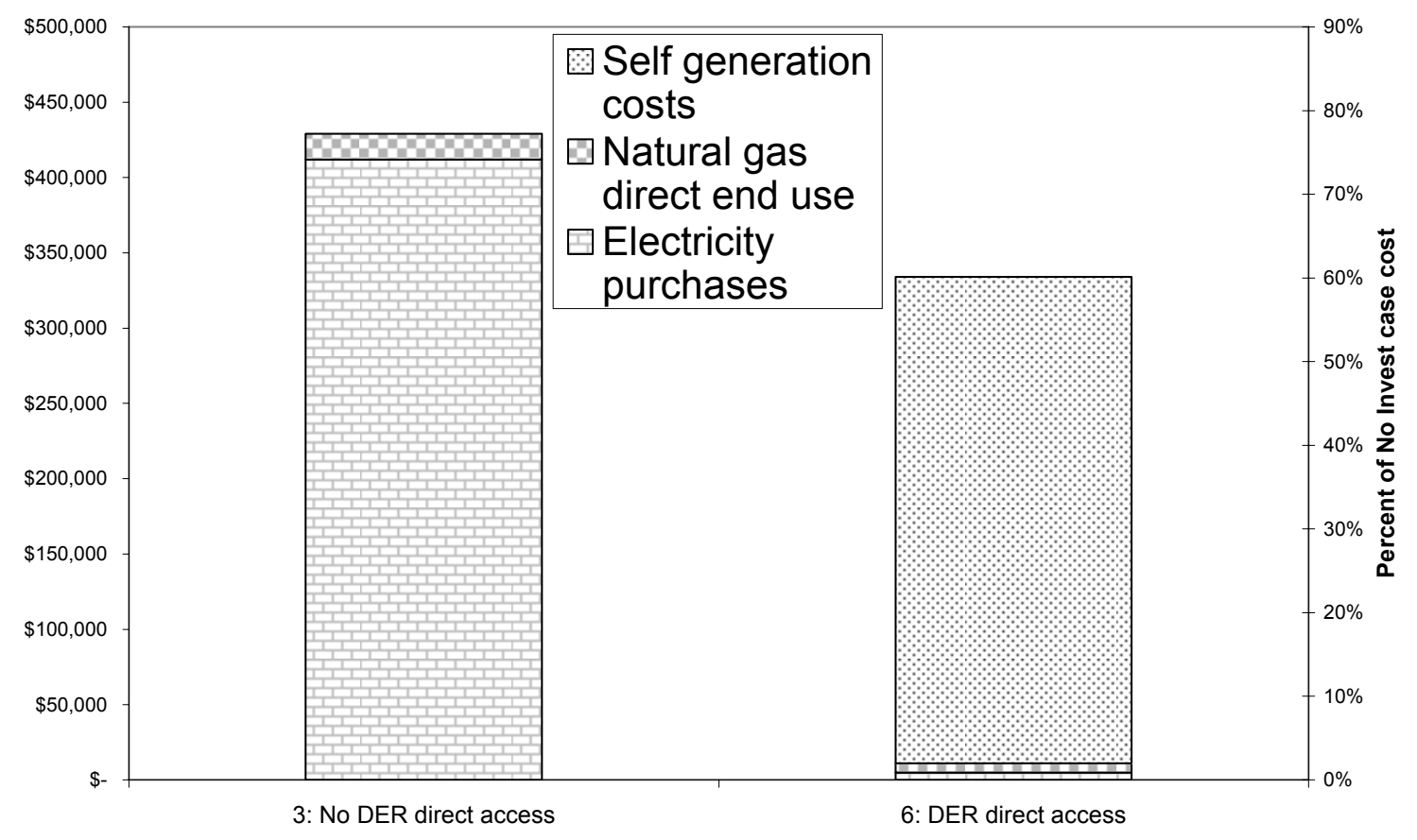

Figure 2: Summary of Results for No DER and DER installation - Separate Refrigeration Load 


\subsection{Results: Integrated Refrigeration Load Model}

Table 4: Building 1512 Annual Energy Consumption and Production Results - Integrated Refrigeration Load

\begin{tabular}{|c|c|c|c|c|c|c|c|c|c|c|c|}
\hline & 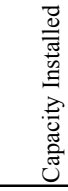 & 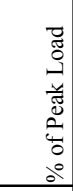 & Equipment & 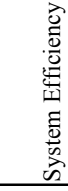 & \multicolumn{3}{|c|}{ Annual Utility Purchase } & \multicolumn{4}{|c|}{ Annual DER Production } \\
\hline & & & & & Electricity & $\begin{array}{l}\text { Gas for } \\
\text { DER }\end{array}$ & $\begin{array}{l}\text { Gas for } \\
\text { direct end } \\
\text { use }\end{array}$ & $\begin{array}{c}\text { Electricity } \\
\text { loads }\end{array}$ & Abs. Cool & $\begin{array}{l}\text { Abs } \\
\text { Refriger- } \\
\text { ation }\end{array}$ & $\begin{array}{c}\text { Thermal } \\
\text { loads }\end{array}$ \\
\hline & $(\mathrm{kW})$ & & & & (MWh) & $(\mathrm{MWh})$ & $(\mathrm{MWh})$ & (MWh) & (MWh) & $(\mathrm{MWh})$ & $(\mathrm{MWh})$ \\
\hline No DER & & & & $35 \%$ & 3,553 & 0 & 426 & 0 & 0 & 0 & 0 \\
\hline DER & 500 & $50 \%$ & $\begin{array}{l}500 \mathrm{~kW} \text { NG engine } \\
\text { with absorption } \\
\text { chiller }\end{array}$ & $60 \%$ & 730 & 7,514 & 147 & 2,438 & 385 & 0 & 279 \\
\hline
\end{tabular}

Note: $1 \mathrm{MWh}=3,600 \mathrm{MJ}=34.13$ therms $=3,412,141 \mathrm{BTU}$

Table 5: Building 1512 Annual Energy Cost Results - Integrated Refrigeration Load

\begin{tabular}{|c|c|c|c|c|c|c|c|c|c|c|c|c|}
\hline & 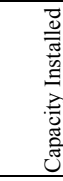 & Equipment & 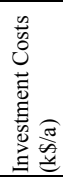 & 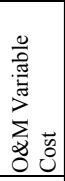 & & al Utility & & & & & & \\
\hline & & & & & Electricity & $\begin{array}{c}\text { Gas for } \\
\text { DER }\end{array}$ & $\begin{array}{c}\text { Gas for } \\
\text { direct end } \\
\text { use }\end{array}$ & $\begin{array}{c}\text { Total } \\
\text { Energy } \\
\text { Costs } \\
\end{array}$ & $\begin{array}{l}\text { Ave. } \\
\text { Elec. } \\
\text { Price }\end{array}$ & \begin{tabular}{|l} 
Bill Savings \\
Over No \\
DER Case \\
\end{tabular} & Payback & $\begin{array}{c}\text { Carbon } \\
\text { Emissions }\end{array}$ \\
\hline & $(\mathrm{kW})$ & & $(\mathrm{k} \$)$ & $(\mathrm{k} \$)$ & $(\mathrm{k} \$)$ & $(\mathrm{k} \$)$ & $(\mathrm{k} \$)$ & $(\mathrm{k} \$)$ & $(\$ / \mathrm{kWh})$ & (\%) & (a) & (t/a) \\
\hline No DER & & & 0 & 0 & 390 & 0 & 15 & 405 & 0.1097 & & & 612 \\
\hline DER & 500 & $\begin{array}{l}500 \mathrm{~kW} \text { NG engine } \\
\text { with absorption } \\
\text { chiller }\end{array}$ & 55 & 41 & 88 & 164 & 8 & 355 & 0.0978 & $12 \%$ & 6.4 & 490 \\
\hline
\end{tabular}




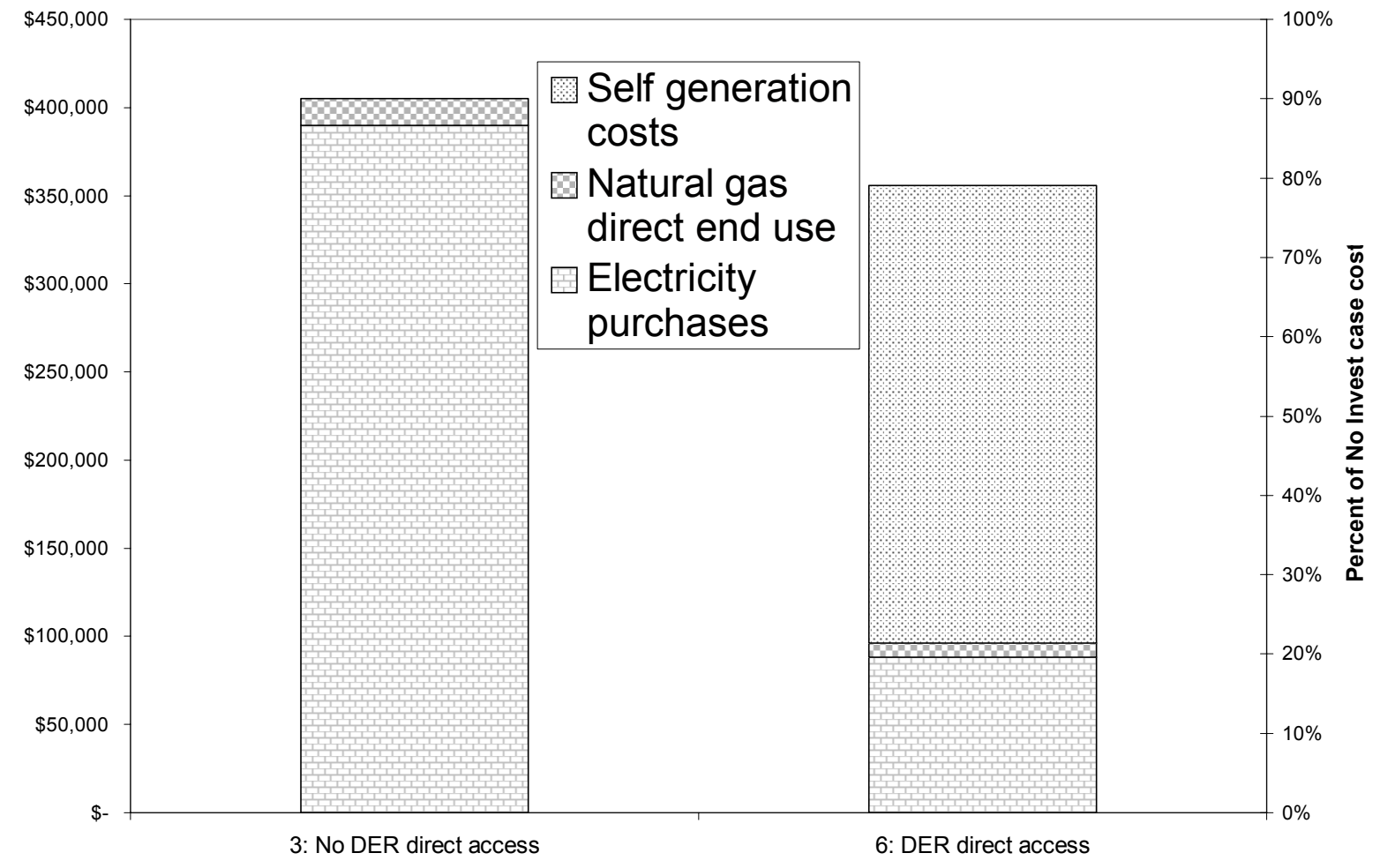

Figure 3: Summary of Results for No DER and DER installation - Integrated Refrigeration Load 


\section{Discussion of Results}

\subsection{Scenario 1 Results: No DER Installation, Separate Refrigeration Load}

In the No DER installation with separate refrigeration load scenario shown in Table 2, Table 3 and Figure 2, the total annual energy bill is $\$ 429,000$ of which $\$ 412,000$ is for electricity and $\$ 17,000$ for natural gas. The average price of electricity is $\$ 0.1073$. The resulting carbon emissions from utility purchase of all electricity and natural gas consumed is 664 metric tons per year. The overall system efficiency is $35 \%$.

The average electricity price is calculated by dividing costs incurred in purchasing or producing electricity by the total electricity consumption, 3,838 MWh per year for the separate refrigeration load model and 3,553 for the integrated refrigeration load model. These electricity costs include the investment, operation and maintenance, and fuel costs of the distributed generation (DG) equipment, along with the cost of purchasing utility electricity including demand charges.

\subsection{Scenario 2 Results: Installation of DER, Separate Refrigeration Load}

Scenario 2 allows installation of DER at Building 1512 with the direct access tariff and separate refrigeration load. Again the results are displayed in Table 2, Table 3, and Figure 2.

For the option of investing in a DER system under a direct access tariff structure, DER-CAM gives an optimal result of $600 \mathrm{~kW}$ installed capacity, comprised of two $300 \mathrm{~kW}$ natural gas engines with absorption cooling and heat recovery capabilities. The system has a high efficiency of $77 \%$ due to the CHP and ample heat loads for absorption cooling and refrigeration. When calculated using the FERC method, efficiency is $54 \%$, well above the $42.5 \%$ needed to qualify for CPUC SelfGen grants. ${ }^{9}$ This scenario has an installed capital cost of about $\$ 889,000$, annualized to $\$ 60,000$ per year over the 20 -year lifetime of the natural gas engines, at a $5 \%$ real interest rate. The operating costs of $\$ 51,000$ reflect the large amount of on-site energy generation and high capacity factor (57\%) for the natural gas engine. Operation and maintenance (O\&M) variable costs rise by $\$ 0.00382 / \mathrm{kWh}$, a $40 \%$ increase for natural gas engines, to account for the SCE departing load charge applied on a $\$ / \mathrm{kWh}$ generated basis. The payback of the DER system is six years.

This system reduces electricity purchases to just $\$ 5,000$ per year, compared to $\$ 412,000$ in No DER. Natural gas consumption, however, increases from $\$ 17,000$ to $\$ 218,000$ to fuel the engines, although residual heat displaces some gas use. The total energy costs are $\$ 334,000$ per year. The DER system installed reduces annual energy expenses by $\$ 95,000$ or $22 \%$, compared to No DER. The payback on the DER system is six years. The average cost of electricity is $\$ 0.0855 / \mathrm{kWh}$. This scenario resulted in carbon emissions of $476 \mathrm{t} / \mathrm{a}$, a reduction of $28 \%$, due to the long operating hours and use of residual heat. The DER equipment produces $3 \mathrm{GWh}$ over the year.

\footnotetext{
${ }^{9}$ This method gives only $1 / 2$ credit for the residual heat production.
} 


\subsection{Scenario 1 Results: No DER Installation, Integrated Refrigeration Load}

In the No DER installation scenario with integrated refrigeration load shown in Table 4, Table 5, and Figure 3, the total annual energy bill is $\$ 405,000$, of which $\$ 390,000$ is for electricity and $\$ 15,000$ for natural gas. The average price of electricity is $\$ 0.1097$. The resulting carbon emissions from utility purchase of all electricity and natural gas consumed is 612 metric tons per year. The overall system efficiency is $35 \%$.

\subsection{Scenario 2 Results: Installation of DER, Integrated Refrigeration Load}

Scenario 2 models the option to invest in DER at Building 1512 with integrated refrigeration load; the results are also displayed in Table 4, Table 5 and Figure 3.

Given the option to invest in DER, DER-CAM returns an optimal result of one $500 \mathrm{~kW}$ natural gas engine with absorption cooling and heat recovery capabilities. The system efficiency is $60 \%$; calculated using the FERC method it is 50\%. This scenario has an installed capital cost of about $\$ 831,000$, annualized to $\$ 55,000$ per year over the lifetime of the equipment at a $7.5 \%$ real interest rate. The natural gas engine has a capacity factor of $46 \%$. Operating costs are $\$ 41,000$ and O\&M variable costs rise by $\$ 0.00382 / \mathrm{kWh}$, a $40 \%$ increase for natural gas engines, to account for the SCE departing load charge that is applied on a $\$ / \mathrm{kWh}$ generated basis. The payback of the DER system is about six and a half years.

This system reduces electricity purchases to $\$ 88,000$ per year, compared to $\$ 390,000$ in No DER direct access. Natural gas consumption increases from $\$ 15,000$ to $\$ 172,000$. Total energy costs are $\$ 355,000$ per year. The DER system installed reduces energy expenses by $\$ 50,000$ per year, or $12 \%$, compared to No DER direct access. The average cost of electricity is $\$ 0.0978 / \mathrm{kWh}$, and carbon emissions are $20 \%$, or 490 t/a. The DER system produces over $2.4 \mathrm{GWh}$ annually. 


\subsection{Sensitivity Analyses}

This section considers the parameters and their ranges that would change the DER system's optimum configuration for both separate and integrated refrigeration loads. It shows the limits under which a system would remain a cost and energy saving option.

In the following graphs, the three generation and heat recovery options are shown in the legend. However, only if a scenario uses more than one generation and recovery option will the graph show more than one of the capacity types. The horizontal axis is the varied parameter value. In some of these sensitivity graphs the horizontal axis is a multiplier on the original parameter value. These original parameter values can be found in the appendix, typically either in Appendix D: Table A-2 Technology Cost and Performance Information, or in Appendix H: Tariff Information. The vertical axis on the left is in $\mathrm{kW}$ to depict the optimal system size or the peak electric load, and the vertical axis on the right is in dollars per year to depict the optimal annual energy cost.

\subsubsection{Separate Refrigeration Load Model}

The sensitivity to DER system cost was determined by increasing the capital and O\&M costs (both fixed and variable) by a set percentage, as presented in Figure 4. The original costs of the DER equipment are provided in Appendix D, Table A-2. The chosen system, two $300 \mathrm{~kW}$ natural gas engines with heating and cooling capabilities, remains optimal up to a $20 \%$ increase in costs. At a $30 \%$ increase, the optimal DER system goes from $600 \mathrm{~kW}$ to $375 \mathrm{~kW}$, by trading one $300 \mathrm{~kW}$ engine for a $75 \mathrm{~kW}$ natural gas engine with heating and cooling capabilities. This system remains robust until DER system costs are at least doubled. At a tripling of DER system costs, DER becomes uneconomical. 


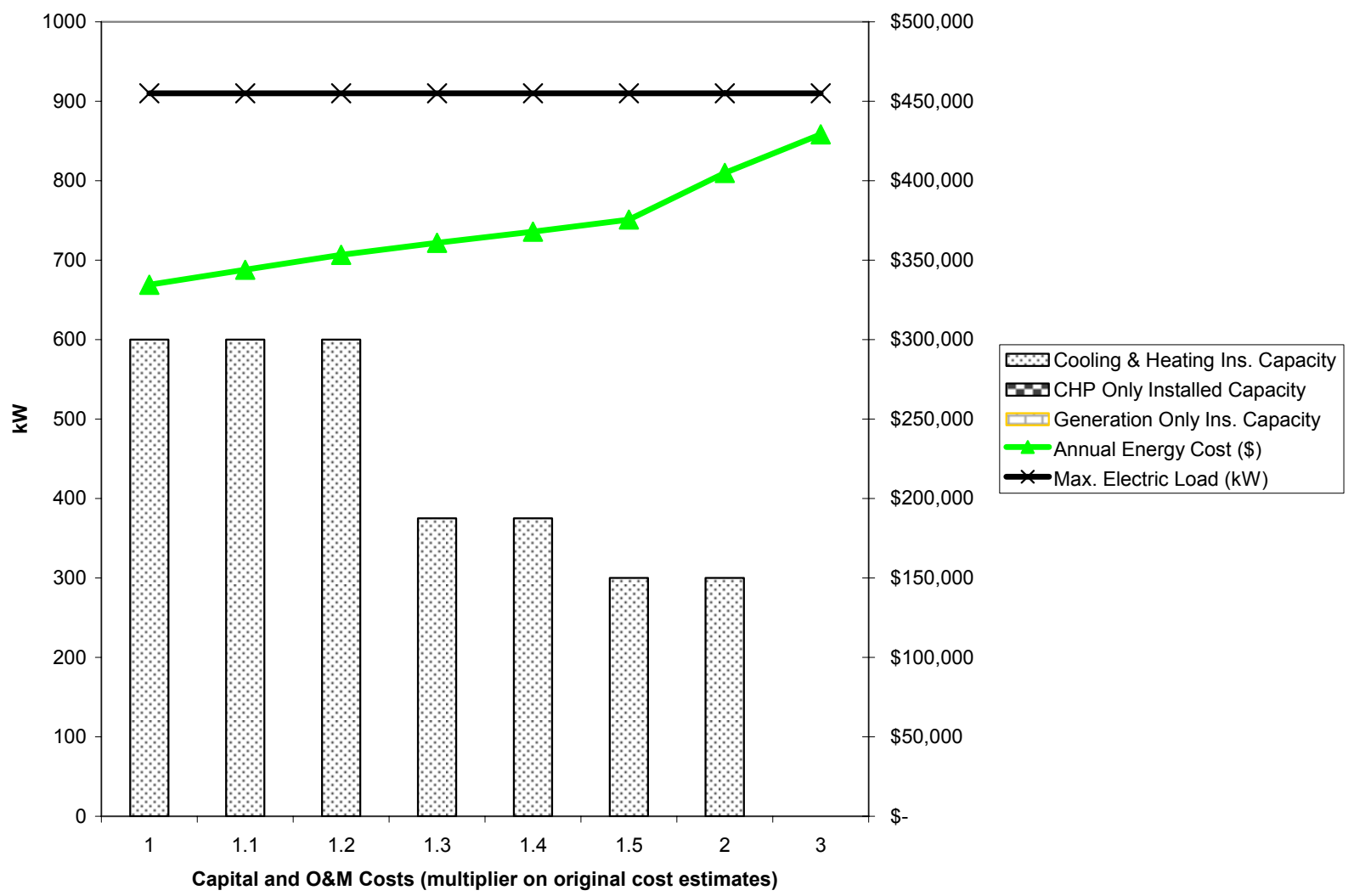

Figure 4: Capital and O\&M Costs Sensitivity - Separate Refrigeration Load 
The DER system's sensitivity to electricity tariff rates was obtained by varying the energy $(\$ / \mathrm{kWh})$ and power $(\$ / \mathrm{kW})$ charges together. These results are presented in Figure 5. A 5\% decrease in costs results in the same optimal DER system, while a $10 \%$ decrease in costs results downsizes the system to $375 \mathrm{~kW}$, still with heating and cooling capabilities. A $20 \%$ decrease results in $300 \mathrm{~kW}$ with cooling and heating capabilities while a $30 \%$ decrease in utility rates makes a DER system uneconomical. A $600 \mathrm{~kW}$ DER system is the optimal system size for tariff increases up to $50 \%$.

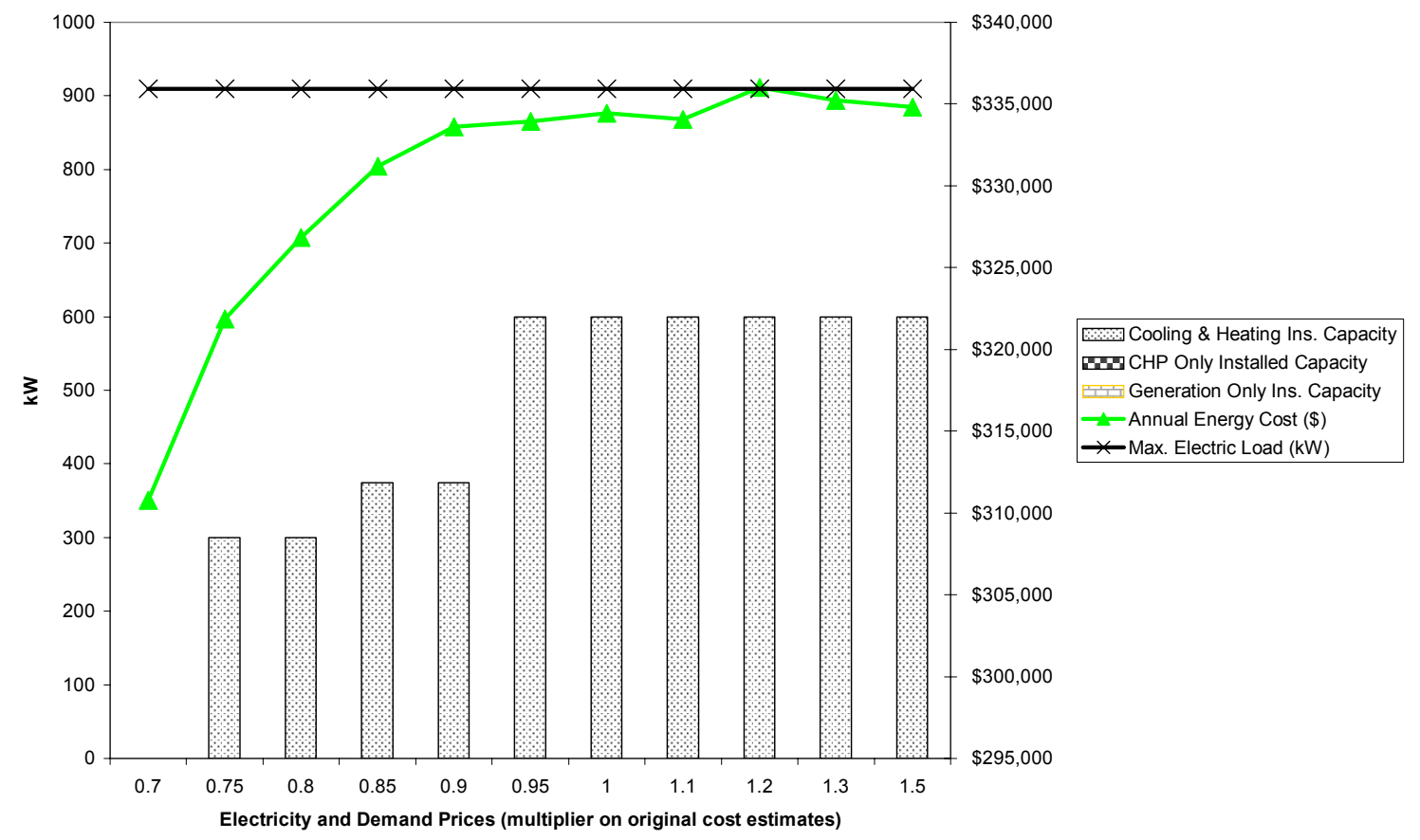

Figure 5: Electricity and Demand Price Sensitivity - Separate Refrigeration Load 
Figure 6 shows DER system sensitivity to changes in natural gas prices. This uses the sparkspread ratio, which shows the relationship of the price of electricity per $\mathrm{kWh}$ to the price of natural gas per $\mathrm{kWh}$. In other words, it describes the difference between the market price of electricity and the fuel cost for DER to produce it. The optimal DER system size is maintained up to a $25 \%$ increase in the price of natural gas and a spark-spread ratio of 4.1 , after which the DER system size is decreased from $600 \mathrm{~kW}$ to $300 \mathrm{~kW}$. The optimal DER system size would remain at $300 \mathrm{~kW}$ until the natural gas price doubles giving a spark-spread ratio of 2.5; at that point DER becomes uneconomical.

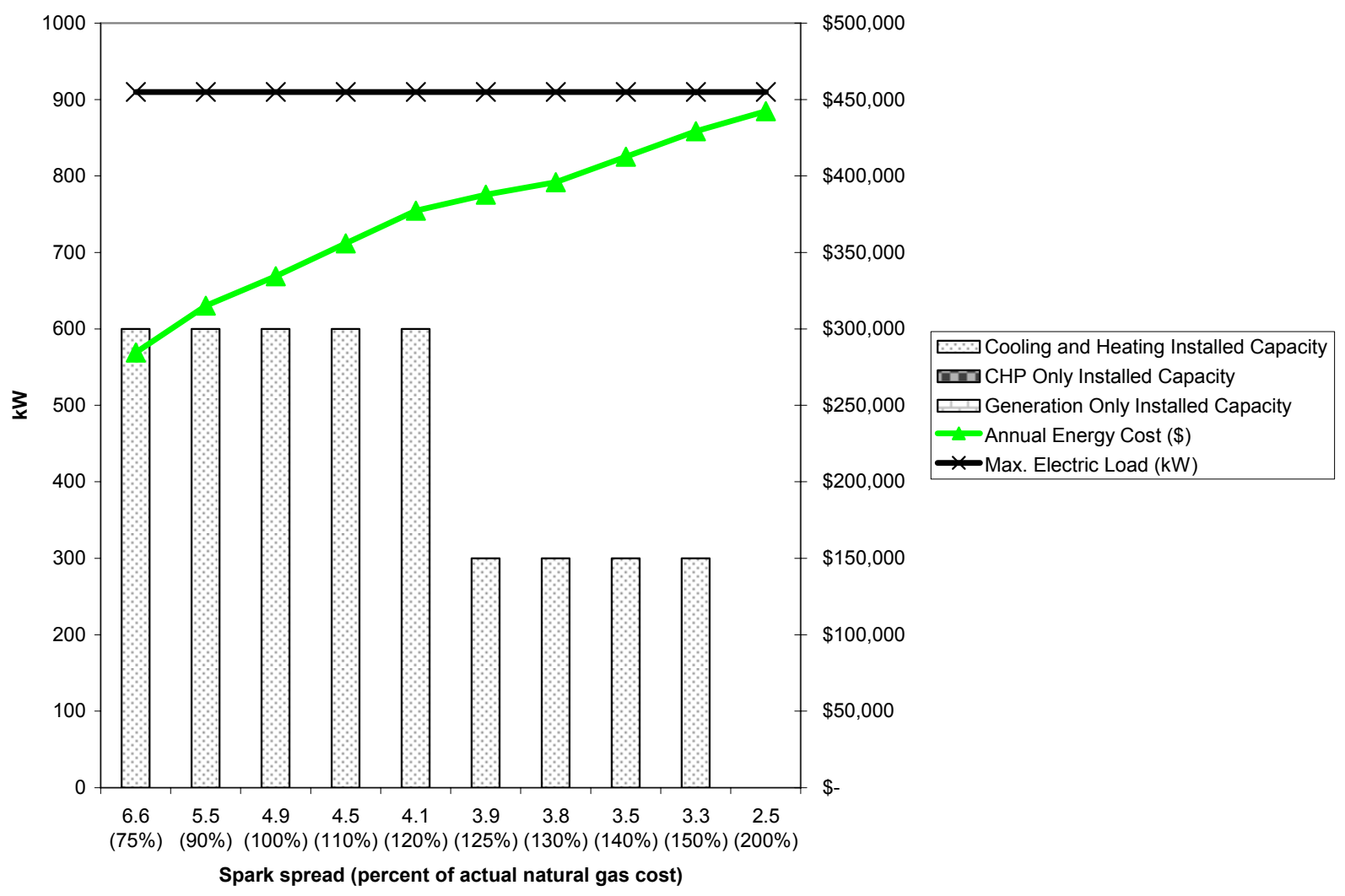

Figure 6: Natural Gas and Spark Spread Sensitivity - Separate Refrigeration Load 
Sensitivity analysis results on standby charge levels are presented in Figure 7. Up to charges of $\$ 2$ per $\mathrm{kW} /$ month, the optimal DER system size remains unchanged at $600 \mathrm{~kW}$. A standby charge between $\$ 3$ and $\$ 5$ per $\mathrm{kW}$ results in a decrease of the optimal DER system size to 400 $\mathrm{kW}$. From $\$ 6$ to $\$ 22$ per $\mathrm{kW}$, the optimal DER system size downsizes to $300 \mathrm{~kW}$, while a standby charge of $\$ 24$ per kW causes the DER system to be uneconomical.

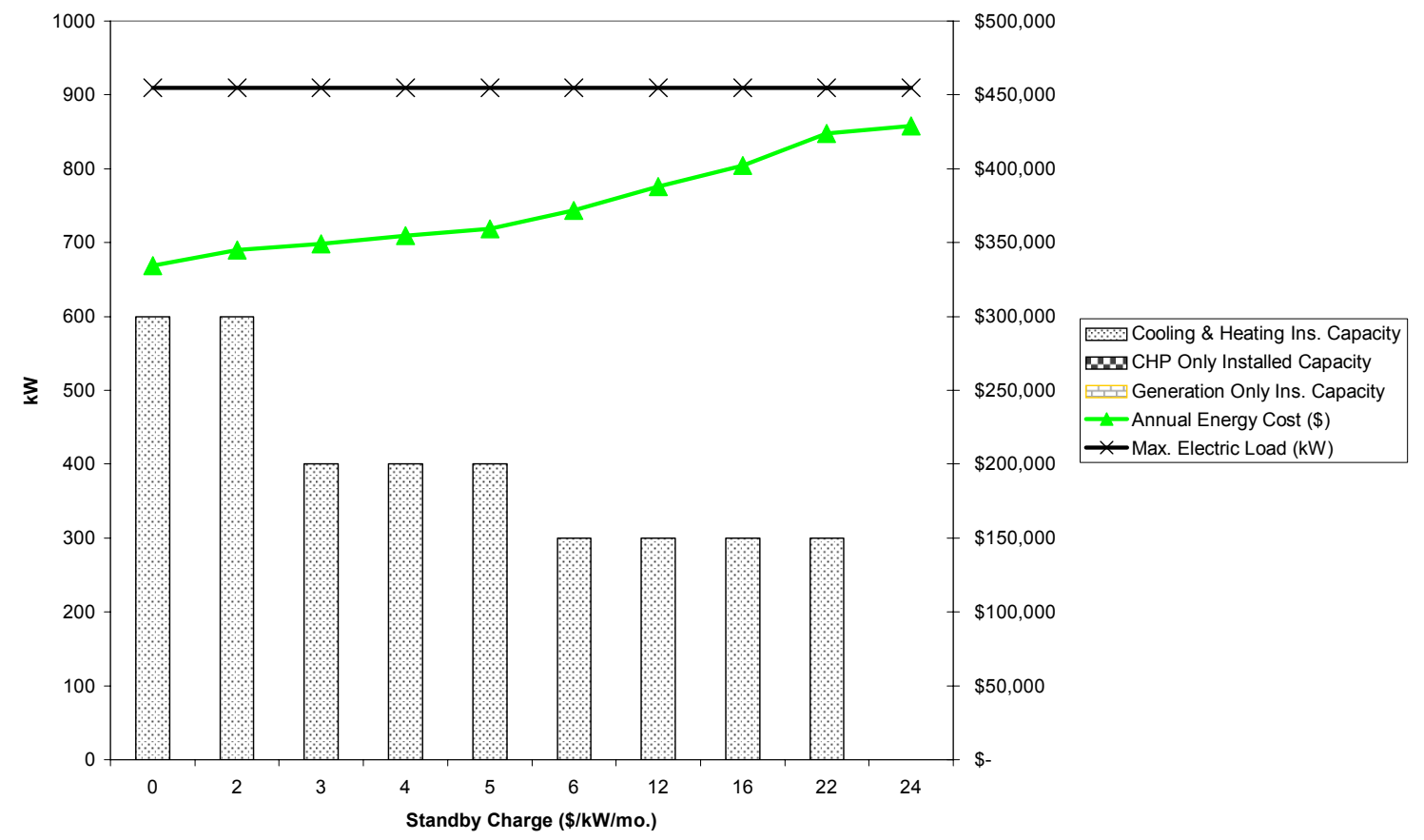

Figure 7: Standby Charge Sensitivity - Separate Refrigeration Load

An increase in the real interest rate for DER investment from 5\% to 7.5\% will not change the optimal installed capacity of a DER system. However, the annual energy cost increases from $\$ 334,000$ to $\$ 345,000$. At a $10 \%$ interest rate, the optimal system size decreases to $400 \mathrm{~kW}$ and the annual DER system cost is $\$ 353,000$.

The DER natural gas engines are assumed to have a lifetime of 20 years over which their capital cost is annualized. The technology lifetime influences the annualized capital cost of the DER equipment. Lowering this assumption to 15 years has no effect on the optimal DER system configuration, but the annual DER system cost increases to $\$ 344,000$. At 10 years, the optimal DER system size becomes $400 \mathrm{~kW}$ with an annual cost is $\$ 358,000$. The results are not shown in figures for the interest rate and lifetime sensitivity analysis. 


\subsubsection{Integrated Refrigeration Load Model}

The results of the sensitivity analysis to DER system capital and O\&M costs are presented in Figure 8. If capital and O\&M fixed and variable costs all increase by $10 \%$, then a $300 \mathrm{~kW}$ natural gas engine with heat recovery and absorption cooling becomes the optimal system design, as opposed to one $500 \mathrm{~kW}$ natural gas engine with standard costs. The $300 \mathrm{~kW}$ natural gas engine remains optimal up to $160 \%$ of original cost estimates and a $\$ 10 / \mathrm{kW} / \mathrm{month}$ standby charge, both applied together.

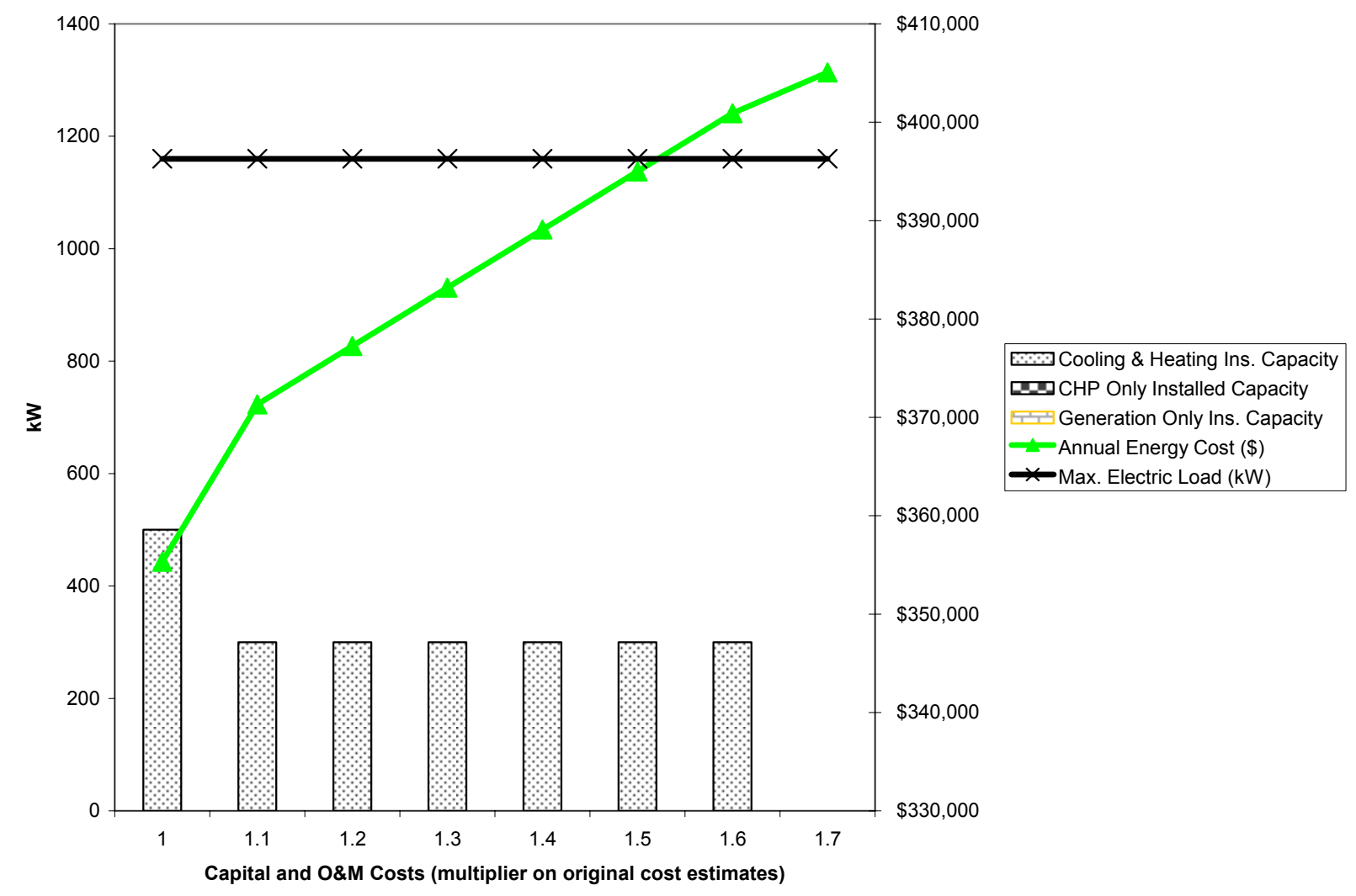

Figure 8: Capital and O\&M Costs Sensitivity Analysis - Integrated Refrigeration Load 
DER system sensitivity to tariff rates is presented in Figure 9. A 15\% drop in energy and demand charges still results in the $500 \mathrm{~kW}$ natural gas engine being optimal. A $20 \%$ drop in energy and demand charges reduces the DER system to a small $30 \mathrm{~kW}$ natural gas engine with heat production capability.

It is not surprising that increases in electricity and demand charges result in corresponding increases in installed capacity in the optimal solutions. A 10\% tariff increase results in adding $100 \mathrm{~kW}$ of natural gas engine with heat production capability. A 20\% increase results in additional $75 \mathrm{~kW}$ natural gas engine with heat production capability for heating and cooling. A $50 \%$ increase results in a total installed capacity of $700 \mathrm{~kW}$ with heating and cooling capability.

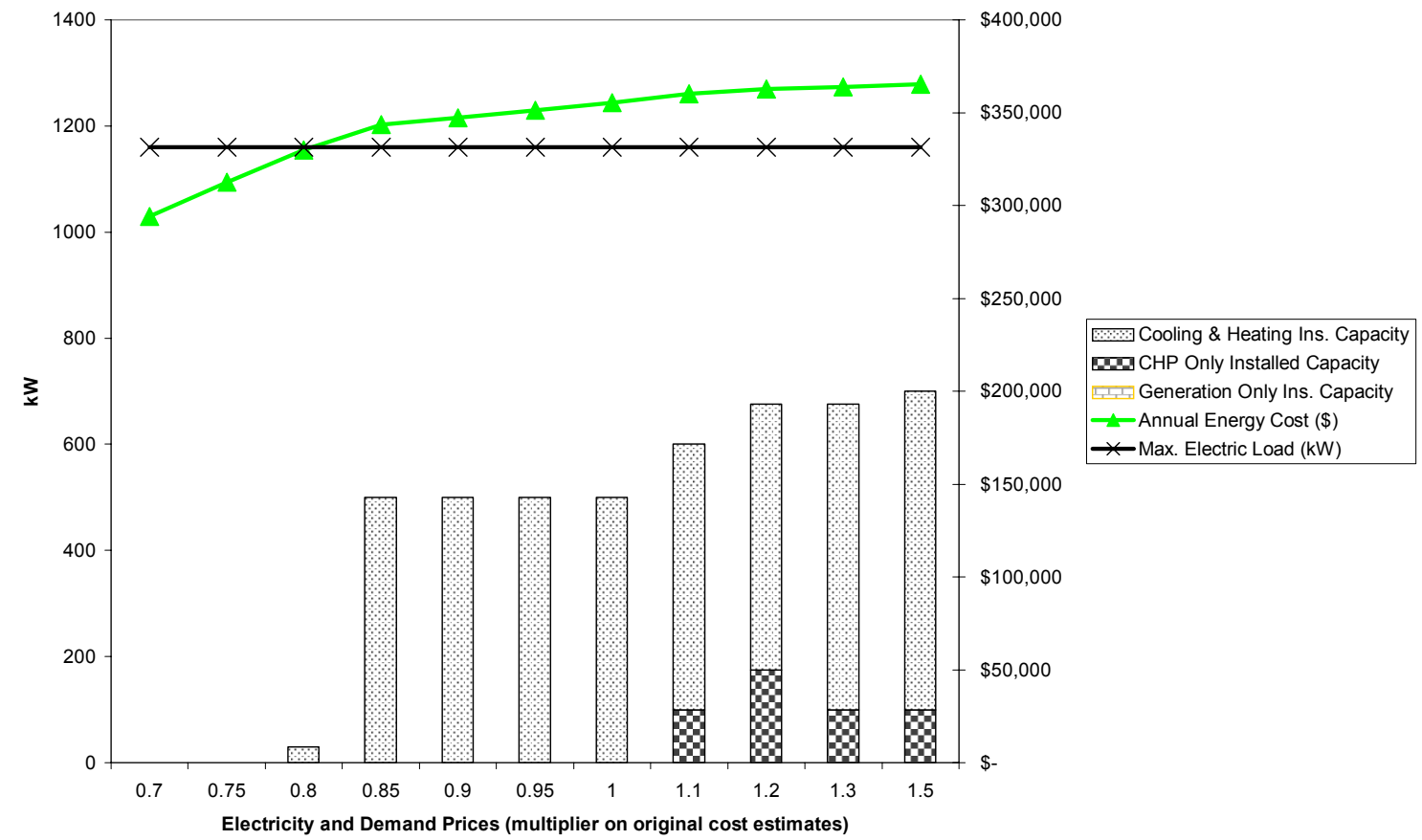

Figure 9: Electricity and Demand Price Sensitivity - Integrated Refrigeration Load 
Spark-spread ratio sensitivity results are presented in Figure 10. As previously noted, the sparkspread ratio shows the relationship of the price of electricity per $\mathrm{kWh}$ to the price of natural gas per kWh. In other words, it describes the difference between the market price of electricity and the fuel cost to produce it.

Up to a $30 \%$ increase in natural gas price, or a spark-spread ratio of 3.9, the $500 \mathrm{~kW}$ natural gas engine is still optimal. However, a $40 \%$ increase raising the spark-spread ratio of 3.6 , forces the optimal DER system down to a $30 \mathrm{~kW}$ natural gas engine with heat production.

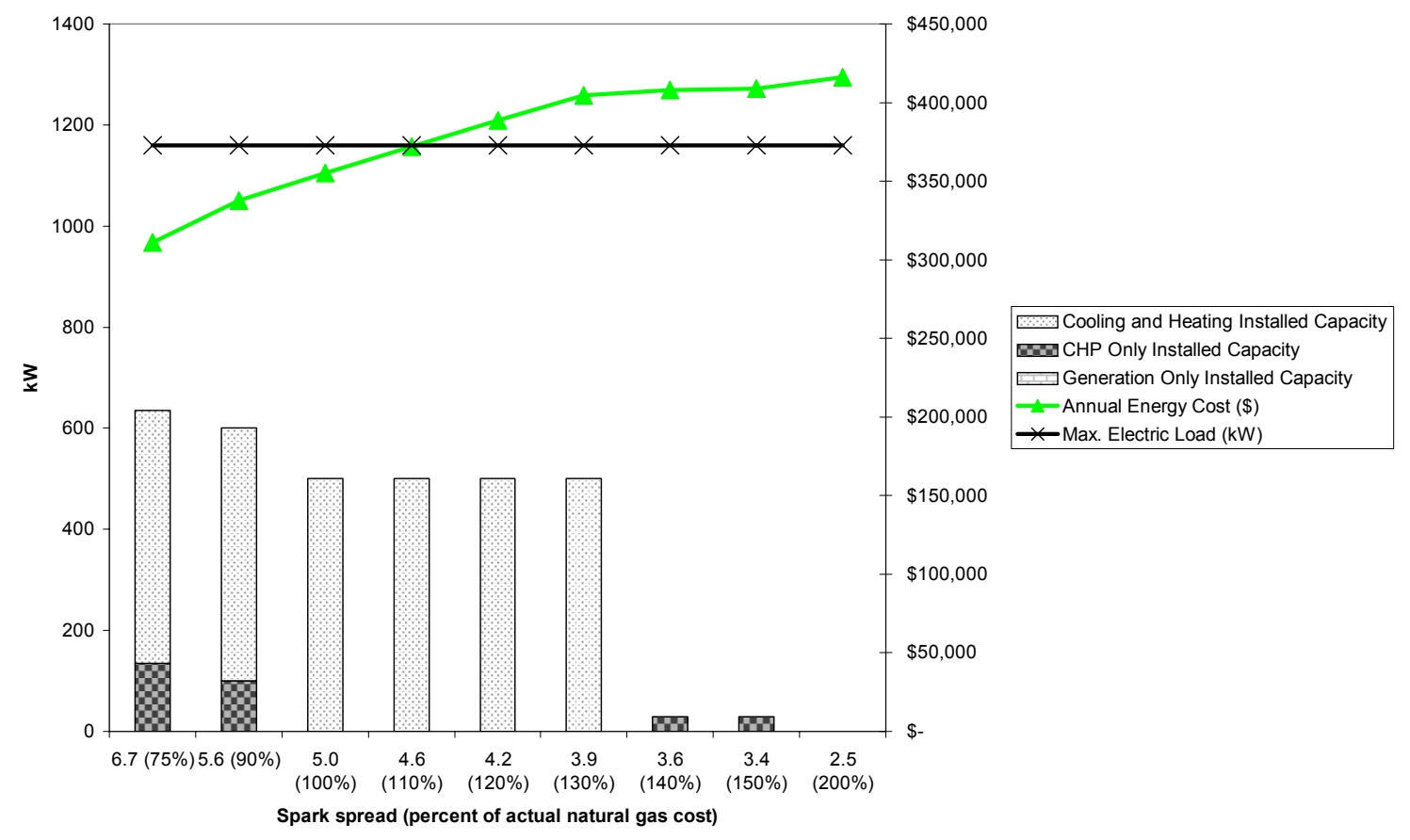

Figure 10: Spark-Spread Ratio Sensitivity Analysis - Integrated Refrigeration Load 
Increasing the standby charge tends to reduce the installed capacity as shown in the standby charge sensitivity results presented in Figure 11. Standby charge rates of $\$ 5 / \mathrm{kW} / \mathrm{month}$ cause a switch from $500 \mathrm{~kW}$ to $300 \mathrm{~kW}$ of installed capacity of a natural gas engine with heating and cooling capabilities. Standby rates of $\$ 12-14 / \mathrm{kW} /$ month start to make DER uneconomical (a 75 $\mathrm{kW}$ natural gas engine with heating and cooling capabilities is optimal), and a $\$ 16 / \mathrm{kW} / \mathrm{month}$ standby charge eliminates DER.

Increasing the interest rate for a DER project tends to make large capital investments less profitable. When the interest rate increases from $7.5 \%$ to $10 \%$, the $500 \mathrm{~kW}$ natural gas engine is still optimal, but becomes uneconomical at a $15 \%$ real interest rate.

The sensitivity of the DER technology lifetime parameter on the optimal solution was also investigated. Reducing the lifetime of the natural gas engines from 20 years to 10 years still results in the $500 \mathrm{~kW}$ unit being optimal.

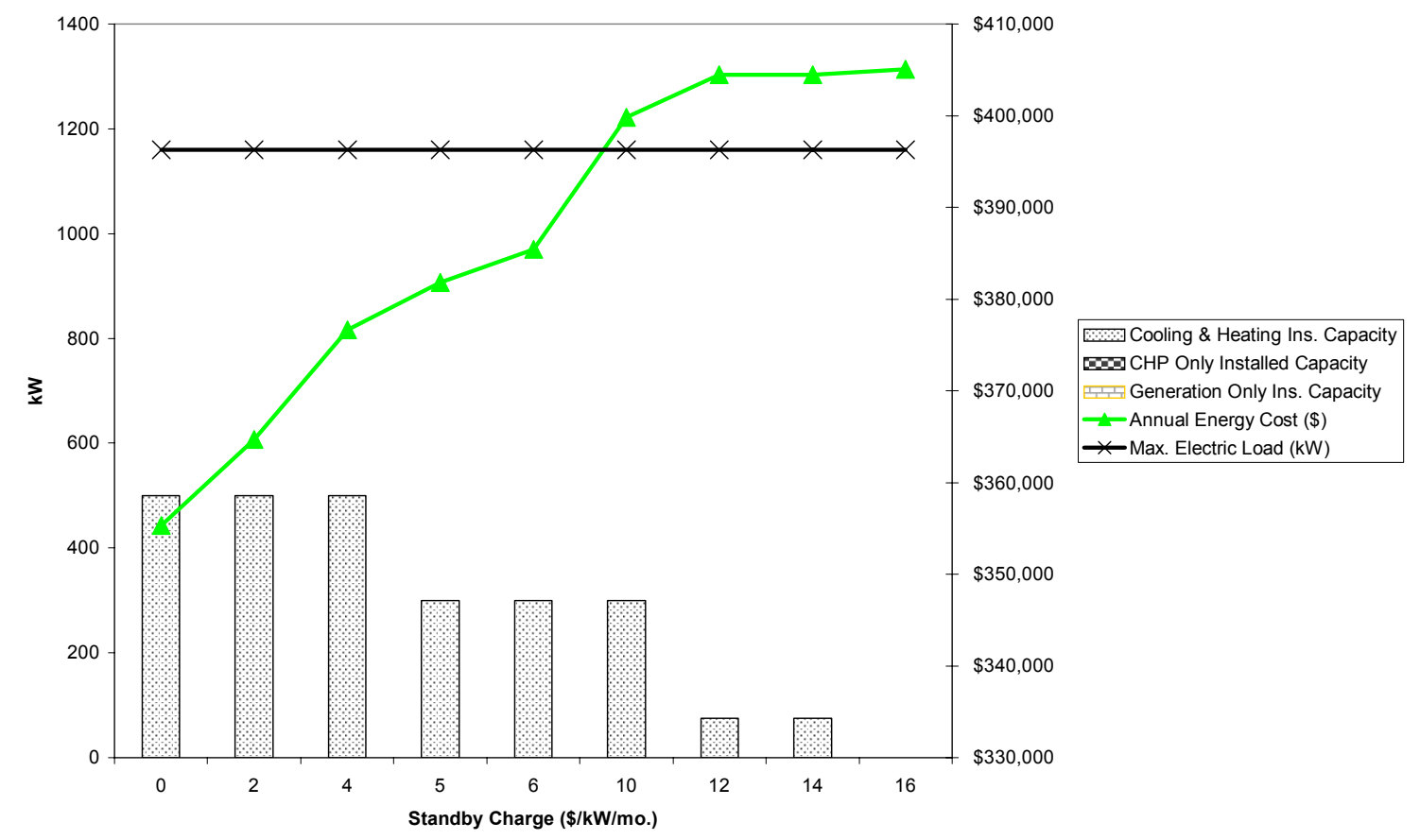

Figure 11: Standby Charge Sensitivity Analysis - Integrated Refrigeration Load

\subsection{Comments}

The DER-CAM optimal solution for the installation of DER with separate refrigeration load scenario is two $300 \mathrm{~kW}$ natural gas engines with absorption cooling and heating capabilities. Installing a DER system will reduce energy costs by $\$ 95,000$ per year, a $22 \%$ savings with a sixyear payback. The DER system will also improve site energy efficiency from $35 \%$ to $77 \%$, reduce carbon emissions by 188 t/a (28\%) and shift Building 1512's power source from nearly 
all electricity to nearly all natural gas. This system is fairly robust since the optimal solution remains the same even if technology costs increase by $20 \%$, natural gas prices rise by $20 \%$, or standby charges go up to $\$ 2 / \mathrm{kW} /$ month. Beyond those critical points, DER-CAM generally decreases capacity to $300-400 \mathrm{~kW}$ of natural gas engines.

Results indicate that absorption refrigeration can be profitably met with residual heat. Absorption cooling efficiency improves when it is serving a sizable, steady, year round load. This use of residual heat appears more economical than using it for electric space cooling which has greater fluctuations. And because electric refrigeration systems are less efficient than electric space cooling systems, greater economic benefits can be gained from using residual heat for absorption refrigeration

Absorption refrigeration offers greater benefits in the separate refrigeration load model than absorption cooling presents in the integrated refrigeration load model. The additional use of residual heat helps to increase system energy efficiency. The DER system provides $776 \mathrm{MWh}$ of absorption refrigeration in the separate refrigeration load model, but less than half that, only 385 MWh, of absorption cooling in the integrated refrigeration load model.

The integrated refrigeration load model is similar to the model analyzed in the previous study of Building 1512. Its optimal solution calls for installing one $500 \mathrm{~kW}$ natural gas engine with absorption cooling and heating capabilities. The result in the DER installation scenario indicates a reduction of annual energy costs by $\$ 50,000$ or $12 \%$ per year, with a six and a half year payback. The site's energy efficiency improves from $35 \%$ to $60 \%$, and carbon emissions go down by $20 \%$ or $122 \mathrm{t} / \mathrm{a}$. This DER system configuration is cost effective if electricity prices increase in the future, standby rates will remain below $\$ 5 / \mathrm{kW} / \mathrm{month}$, and cost of capital is $10 \%$ real interest rate or less.

If the main concerns are DER system cost overruns, installing one $300 \mathrm{~kW}$ natural gas engine with absorption cooling and heating capabilities is the more conservative choice. The $300 \mathrm{~kW}$ generator is also recommended if standby rates are predicted to remain below $\$ 10 / \mathrm{kW} / \mathrm{month}$ or gas prices are expected to increasing substantially (greater than 20\%).

This analysis shows that financial, energy, and environmental savings may be obtained by installing a DER system at the site. The ability to use the residual heat to displace expensive electricity-driven cooling systems is important to increasing the overall economic outlook from a meager savings of $\$ 50,000$ per year to a more compelling $\$ 95,000$ per year. Therefore, assessing the technical and financial feasibility of using an absorption refrigeration system at Building 1512 is crucial to evaluating installation of a DER system at the site.

This analysis also shows the energy source for the building shifts from almost all electricity (as it is now) to almost all natural gas with a DER installation. The DER system would also reduce electricity purchases from the grid substantially to between $12 \mathrm{kWh}$ (separate refrigeration model) and $730 \mathrm{MWh}$ (integrated model) annually. The overall energy efficiency would also increase substantially to the range of 60 to $77 \%$ with an accompanying reduction in overall carbon emissions near 150 t/a. 


\section{Conclusion}

The preliminary assessment of the cost effectiveness of distributed energy resources at Naval Base Ventura County (NBVC) Building 1512 indicates an opportunity for cost reductions and energy efficiency improvements from a DER system. ${ }^{10}$ These sensitivity analyses on key parameters, including the effectiveness of meeting refrigeration loads with absorption refrigeration, analyzes two systems: one where refrigeration loads could be served with absorption cooling and one with refrigeration loads integrated into the site's electricity load.

This analysis shows that financial, energy, and environmental savings can be realized by installing a DER system at the site. At current tariff rates, and given assumptions about the building's energy loads and the performance of available technologies, the results of the study indicate that if DER were installed, the cost savings would be approximately $12 \%$ in the integrated refrigeration load model. The energy savings would rise to $22 \%$ if the refrigeration loads can be served with absorption cooling.

The optimal DER system size for the site would be between $300 \mathrm{~kW}$ and $600 \mathrm{~kW}$ with heating and absorption cooling capabilities, depending on future electricity and natural gas prices, tariff components such as demand and standby charges, the expected capital costs, and whether or not the residual heat would be used for absorption refrigeration.

The ability to use residual heat, especially to displace expensive electric-driven cooling systems, is an important factor in the financial evaluation of a DER system, and a more detailed engineering feasibility analysis of an absorption refrigeration system should be performed.

Since the DER system's cost effectiveness is tied to use of residual heat, it makes sense to find other nearby heat loads, particularly those displacing expensive electric cooling systems. Several buildings near Building 1512 have substantial heat or electricity loads. These include office buildings, laundromat, swimming pool facility, gymnasium, fast food restaurant, and gas station.

The opportunity to improve reliability and power quality by backing up critical loads or serving them full time may also drive the decision to install DER. These benefits would be specific to the building and operations performed and may be more difficult to quantify.

At present, no information is collected on power demand or hour-by-hour energy consumption at Building 1512. Energy consumption (kWh) data is collected on a monthly basis for electricity and natural gas. The current direct access tariff charges the same energy rate for each time period so demand charges do not appear to contribute greatly to energy bills. However, more detailed and frequently collected electricity data, such as available from electronic meters, could yield useful information on energy consumption patterns and load shapes for the building to guide decisions about energy efficiency and demand response programs or implementing a DER system. Faster acquisition of utility consumption data could also help spot and quickly correct problems with the building's energy systems before they impact areas other than utility bills, such as customer comfort or grocery inventory.

\footnotetext{
${ }^{10}$ Bailey and Marnay, 2004.
} 
As noted in the previous study, on-site power generation would shift the building's energy source from almost all electricity (as it is now) to mostly natural gas for generation. A rate structure or commodity price change could easily increase the energy bill by $\$ 50,000$ a year, roughly the difference in annual energy costs between Building 1512's electricity bill on its current direct access contract and the DER installation scenario. This is the same magnitude of savings between the annual energy costs of Building 1512's electricity bill on its current direct access contract versus the default SCE TOU-8 rate. Therefore, electricity and natural gas tariff rates and contracts at NBVC should be studied carefully as part of finding cost savings and efficiency improvements because these factors greatly influence energy costs and the financial value of a DER system. 


\section{References}

A.D. Little. March 2002. "Global Comparative Analysis of HFC and Alternative Technologies for Refrigeration, Air Conditioning, Foam, Solvent, Aerosol Propellant, and Fire Protection Applications." Final Report to the Alliance for Responsible Atmospheric Policy. http://www.arap.org/adlittle/toc.html

Bailey, O.C. and C. Marnay. August 2004. "Distributed Energy Resources at Navy Base Ventura County Building 1512.” Berkeley Lab Report LBNL-55340.

Bailey, O. C. Creighton, R. Firestone, C. Marnay, and M. Stadler. February 2003. "Distributed Energy Resources in Practice: A Case Study Analysis and Validation of LBNL's Customer Adoption Model. Berkeley Lab Report LBNL-52753.

CBC Meter Readings FY 03 and FY 04. Provided by Deborah Stewart, Public Utilities Specialist, NBVC. December 2003 and March 2004.

Firestone, Ryan. January 2004. "Distributed Energy Resources Customer Adoption Model Technology Data." http://der.lbl.gov/tech_data.html.

Goldstein, L., B. Hedman, D. Knowles, S.I. Freedman, R. Woods, T. Schweizer. 2003. "Gas-Fired Distributed Energy Resource Technology Characterizations" Golden, CO: National Renewable Energy Laboratory report NREL/TP-620-34783.

Hui, S.C.M.. “DOE-2.1E Basics Manual.” August 2001. http://gundog.lbl.gov/ referenced 13 May 2004 from the Building Simulation Group web page at Berkeley Lab.

NBVC Public Works. “Top Utility Consumers for FY 03.” Received December 2003.

NBVC Public Works. "Interim Installation Assessment Report.” Received December 2003.

PM Meter Readings FY 03. Provided by Deborah Stewart, Public Utilities Specialist, NBVC. December 2003.

Southern California Edison. SCE TOU-8 and SCE TOU-8 Direct Access tariffs and Departing Load reference document provided by Nathan Smith at SCE.

Nathan.Smith@sce.com.

Southern California Gas Company. August 2001. "Naval Base Ventura County Standby Generator Optimization Review."

Sweetser, Richard. Use of a Cooling, Heating, and Power System in a Supermarket. Presentation at DOE/CETC Workshop on Microturbine Applications. January 2004. 



\section{Appendix A. Model Structure}

\section{A.1.1 Three Day Type Model}

DER-CAM has three day types: weekday, peak day, and weekend. Week and weekend days are obtained by averaging data from all the days of that type, for each hour, into a representative day with an hourly profile. Hence, the week and weekend days are average days. Peak days represent the three highest load days of each month. The peak day for each month was observed in the DOE-2 output and replicated as the peak day.

The representative load profile for each day type was multiplied by the number of days of each type per month in 2004 to obtain the total energy load use for each of the five end uses. The three peak days were obtained by subtracting two days from the week days and one day from the weekend totals. Exceptions were February, August, and October, where the two peak days were taken from the weekend days and one peak day from the week day, because these months had weekend peaking loads in DOE-2 for each of the three buildings simulated. The number of each day type was multiplied by the total load of each type for each month to determine the total load for that month. These values were then summed and compared to the average meter read data obtained from Public Works. Adjustments to the DOE-2 load data were made to compensate for the difference between the model data and the averaged meter read data. The DOE-2 model estimates were close to the average of the meter data. Electricity-only and cooling loads were multiplied by 0.96 and space-heating, water-heating, and natural-gas-only loads were multiplied by 0.85 to correspond with average electric and natural gas meter data.

\section{A.1.2 Interest Rate}

The interest rate used for calculating the annual cost of capital equipment was 5\% real compounded annually for the separate refrigeration load model and $7.5 \%$ for the integrated refrigeration load model.

\section{A.1.3 Parameter Inputs to DOE-2}

DOE-2 also needs a set of parameters for weather and floor space. The Santa Maria CA TMY2 weather file was used because it most closely matches the weather at the bases. Building 1512's floor space was assumed to be divided among the NEX, Commissary, and Food Court according to Table A- 1.

Table A- 1: Area of each Section of Building 1512

\begin{tabular}{|l|c|}
\hline Building & Size $\mathbf{~ m}^{\mathbf{2}}\left(\mathbf{f t}^{\mathbf{2}}\right)$ \\
\hline NEX & $7,600 \quad(82,000)$ \\
\hline Commissary & $4,500(49,000)$ \\
\hline Food Court & $500 \quad(5,400)$ \\
\hline
\end{tabular}





\section{Appendix B. $\quad$ Assumptions in Modeling Process}

\section{B.1.1 Assumptions Made for Modeling Building 1512 at NBVC}

Modeling Building 1512 required the following parameter input assumptions:

- The load, tariff, technology and other input parameter characterizations are correct and unchanging over the analysis period.

- The financial analysis is performed over a period of one year with the DER equipment capital cost amortized over the 10 to 30 year lifetime of the equipment.

- The process assumes the DOE-2 output is correct and linearly scalable. In other words, when energy use estimates disagree with actual data, the load profiles are still valid and can be scaled to meet actual data.

- All decisions are made in the same year: all technology, load, and tariff information is concurrent.

- Perfect information is assumed in the decision-making process: all technology cost and performance data is accurate and known by all the decision makers involved in the process. Furthermore, a DER system's cost does not change during a project installation period or after it is operating.

- All technologies in the model are one of three types depending upon the output produced: DG (electricity only); DG with CHP (heat recovery) capability; or DG, CHP, and absorption cooling capability.

- The DER system, if installed, will be a retrofit to work in conjunction with the existing heating and cooling systems in each building. The Commissary and NEX would connect the new generating equipment to the existing natural-gas-fired boiler or furnace to meet residual heating loads, and to a compressor driven air conditioning system currently used to meet space-cooling loads. The existing equipment operates at average efficiency.

- Absorption cooling is used to displace compressor cooling for air conditioning and refrigeration. However, to avoid altering the cooling load input data, absorption cooling is also assigned a certain "phantom" electrical output at zero cost. This should result in the model accurately representing capital and operating costs and performance characteristics of absorption cooling equipment while simultaneously substituting for electricity powered cooling equipment without affecting the electrical load data. The electrical load data are entered in the model and mixed integer programming optimization models are not able to modify the input data.

- Since the performance of the DER systems is typically given at maximum capacity in the specification sheets, each DER unit operates at constant efficiency and COP over the range of output. That is, the amount of heating or cooling a unit produces is proportionally related 
to the percent of electrical capacity the unit is producing. The ratio of heating or cooling output per unit of electric output is also assumed fixed; the efficiency of fuel input and energy output per unit of electricity production capacity are assumed fixed throughout the technology's operating capacity.

- The DOE-2 model accurately estimates the heating and cooling loads for each particular site, and only the specific portions of those loads that can be met with CHP are selected. Other loads are included in the model as "natural-gas-only loads." The heating and cooling loads developed for this model are accurate for the buildings.

- The manufacturer performance specifications are correct and the price estimates are representative for the area and time period studied. Capital costs in $\$ / \mathrm{kW}$ are turnkey costs with system design, purchase and installation included.

- The DER equipment maintains a load-following capability. That is, electric loads are met with DER output, while heating and cooling needs are met with a combination of CHP output (also based on electricity production) and assistance from the supplementary heating and cooling systems.

- Ancillary loads of absorption chillers are ignored because a standard absorption cooling system uses substantially less energy than a compressor cooling system.

- Since the building has no thermal heat storage, heating and cooling load must be met with production for each hour of the day. However, heating and cooling loads can be reduced during off peak hours to reflect the reduced demand at those times.

- Heat flow is modeled using kW (power) on an hourly basis. All heat has the same quality; it flows where it is directed and is delivered with efficiency of parameter $\gamma$ to loads, where $\gamma$ is equal to 0.8 for CHP-served heating loads and 0.13 for absorption chiller served cooling loads. The temperatures, flow rates, and pressures of heat transfer mediums are ignored. The specific types and capacities of the thermal end use, temperatures, flow rates, distances, pressures, and efficiency curves can be important in a specific application but are not included in this model. For example, the inlet temperatures of hot water (cooling loop) or chilled water (absorption cooling) are assumed to be ideal.

\section{B.1.2 Assumptions Made for Efficiency Calculations}

The following assumptions were used in calculating energy efficiency for the system:

- The efficiency values sited are whole system efficiencies that include loads served and fuel required by the macrogrid, natural gas delivery network, and the on-site DER system.

- Efficiency is calculated by summing all the end-use load requirements in $\mathrm{kWh}$ for both electric and gas, then dividing by the fuel requirement for each load. The macrogrid's efficiency is 0.33 . The fuel requirement is derived by dividing the load by the efficiency, thereby calculating the primary fuel input as a function of efficiency. Fuel consumed and 
electricity produced by the DER system are provided as DER-CAM output. Natural gas loads are also provided as a DER-CAM output and are met with purchases delivered on site with an efficiency of 1 (natural gas to natural gas load). The delivery efficiency of the natural gas transportation network is assumed to be 0.8 . Hence, the primary fuel requirements necessary to serve the natural gas loads are found by dividing the load by 0.8 .

- Thermal loads met by CHP are also provided as output from DER-CAM. They do not require additional fuel input since it has already been included.

- DER system efficiency, if cited, is calculated by adding the electricity output of the DER equipment to the thermal loads served by CHP (in $\mathrm{kWh}$ ) and dividing by the fuel consumed to run the DER equipment. This is a more focused view of the DER system efficiency and does not include the efficiency of the natural gas delivery infrastructure.

- Carbon emissions are calculated from the fuel input requirements. Electric energy is assumed to produce $0.165 \mathrm{~kg} / \mathrm{kWh}$ and natural gas $0.048 \mathrm{~kg} / \mathrm{kWh}$. 



\section{Appendix C. Limitations of Analysis}

Actual data for the different end-use loads was not available, especially on the hourly basis DERCAM requires as input. DOE-2 building simulation was used to generate estimates of these loads. They were then scaled to reflect the magnitude of the data from the electric and gas meters each month at Building 1512. This process developed rough load curves for the building but may have missed some of important characteristics which should be integrated with a DER system. Refrigerator, freezer and chilled display case loads in the Commissary and NEX, for example, would make substantial loads for a residual heat driven absorption chiller. The DOE-2 modeling method used to generate building loads for DER-CAM, however, considers the electricity used by these coolers to be electricity-only loads which cannot be met by an absorption chiller. Hence these loads were separated and served with specific performance measures derived from analysis of systems with refrigeration loads assisted by absorption chillers.

If further analysis with $\mathrm{PV}$ is to be completed accurate data for insolation, the amount of incoming solar radiation received by an exposed surface, should be obtained. Values for Southern California (San Diego) were used in this study because no data are available for Port Hueneme.

The analysis uses historic estimated loads and assumes electricity and gas tariffs are constant throughout the year. Viewing historical electricity and gas bills reveals that the commodity prices of electricity and natural gas both fluctuated greatly over the last twelve months.

Technology installed capital costs are general and may not reflect site-specific conditions that will influence the technology configuration and the design and installation costs. 



\section{Appendix D. Technology Performance and Price Information ${ }^{11}$}

\section{D.1 Technology Performance and Price Parameters}

To be consistent across technologies, DER technology capital costs and performance specifications are primarily taken from Goldstein et al. (TeChars). Table A- 2 describes the technology cost and performance information used in DER-CAM. The CPUC SelfGen grants were then included, reducing the capital cost of applicable technologies.

Table A- 2: DER-CAM Technology Cost and Performance Information

\begin{tabular}{|c|c|c|c|c|c|c|c|c|c|c|c|c|c|}
\hline \multicolumn{14}{|c|}{\begin{tabular}{|l|} 
Color Key \\
Data From NREL Technology Characterizations \\
Remaining DER-CAM Data Requirements \\
Not Applicable \\
\end{tabular}} \\
\hline & & $\begin{array}{l}\operatorname{maxp} \\
(\mathrm{kW})\end{array}$ & $\begin{array}{l}\text { lifetime } \\
\text { (years) }\end{array}$ & \multirow{2}{*}{\multicolumn{3}{|c|}{\begin{tabular}{|l|r|l|}
\begin{tabular}{|l|l|} 
Electricity \\
Only
\end{tabular} & $\begin{array}{l}\text { CHP for } \\
\text { Heating }\end{array}$ & $\begin{array}{l}\text { CHP for } \\
\text { Heating } \\
\text { and } \\
\text { Cooling }\end{array}$ \\
5005 & 5200 & 5366 \\
\end{tabular}}} & $\begin{array}{l}\text { OMFix with } \\
\text { Abs. } \\
\text { Cooling } \\
(\$ / k W \text { a) }\end{array}$ & $\begin{array}{l}\text { OMFix } \\
\text { without } \\
\text { Abs. } \\
\text { Cooling } \\
\text { (\$/kW a) }\end{array}$ & $\begin{array}{l}\text { OMVar } \\
\text { (\$/kWh) }\end{array}$ & \begin{tabular}{|l} 
HeatR \\
$(\mathrm{kJ} / \mathrm{kWh})$
\end{tabular} & Fuel* & Type & $\begin{array}{l}\text { Alpha for } \\
\text { CHP } \\
\text { units }\end{array}$ \\
\hline Fuel Cells & FC-200 & 200 & \begin{tabular}{r|}
10 \\
\end{tabular} & & & & 9.69 & 0 & $\begin{array}{l}0.029 \\
\end{array}$ & 10000 & 1 & \begin{tabular}{|l}
1 \\
\end{tabular} & 1.25 \\
\hline \multirow[t]{5}{*}{ Gas Turbines } & GT-01000 & 1000 & 20 & 1403 & 1910 & 2137 & 10.37 & 0 & 0.0096 & 16438 & 1 & 1 & 2.45 \\
\hline & GT-05000 & 5000 & 20 & 779 & 1024 & 1149 & 4.03 & 0 & 0.0059 & 13284 & 1 & 1 & 1.84 \\
\hline & \begin{tabular}{|l|} 
GT-10000 \\
\end{tabular} & 10000 & 20 & 716 & 928 & 1025 & 2.76 & 0 & 0.0055 & 12414 & 1 & 1 & 1.71 \\
\hline & GT-25000 & 25000 & 20 & 659 & 800 & 859 & 2.12 & 0 & 0.0049 & 10496 & 1 & 1 & 1.32 \\
\hline & GT-40000 & 40000 & 20 & 592 & 702 & 746 & 1.88 & 0 & 0.0042 & 9730 & 1 & 1 & 1.17 \\
\hline \multirow[t]{5}{*}{ Microturbines } & \begin{tabular}{|l|} 
MT-028 \\
\end{tabular} & 28 & 10 & 2263 & 2636 & 3046 & 23.49 & 0 & 0.015 & 15929 & 1 & 1 & 2.40 \\
\hline & MT-060 & 60 & 10 & 1828 & 2082 & 2420 & 19.50 & 0 & 0.015 & 14400 & 1 & 1 & 2.24 \\
\hline & MT-067 & 67 & 10 & 1708 & $\begin{array}{ll}1926 \\
\end{array}$ & 2201 & 15.87 & 0 & 0.015 & 14286 & 1 & 1 & 1.79 \\
\hline & MT-076 & 76 & 10 & 1713 & 1932 & 2225 & 16.92 & 0 & 0.015 & 14876 & 1 & 1 & 1.98 \\
\hline & MT-100 & 100 & 10 & 1576 & 1769 & 2015 & 14.27 & 0 & 0.015 & 13846 & 1 & 1 & 1.71 \\
\hline \multirow[t]{8}{*}{ Natural Gas Engines } & NG-030 & 30 & 20 & 1044 & 1442 & 2029 & 22.56 & 0 & 0.02 & 13080 & 1 & 1 & 2.32 \\
\hline & NG-060 & 60 & 20 & 991 & 1362 & 1851 & 18.93 & 0 & 0.018 & 12528 & 1 & 1 & 2.16 \\
\hline & NG-075 & 75 & 20 & 974 & 1336 & 1796 & 17.84 & 0 & 0.017 & 12360 & 1 & 1 & 2.11 \\
\hline & \begin{tabular}{|l|} 
NG-0100 \\
\end{tabular} & 100 & 20 & 1030 & 1350 & 1774 & 16.51 & 0 & 0.018 & 12000 & 1 & 1 & 2.05 \\
\hline & NG-0300 & 300 & 20 & 790 & 1160 & 1465 & 12.08 & 0 & 0.013 & 11613 & 1 & 1 & 1.85 \\
\hline & NG-1000 & 1000 & 20 & 720 & 945 & 1117 & 6.97 & 0 & 0.009 & 10588 & 1 & 1 & 1.36 \\
\hline & NG-3000 & 3000 & 20 & 710 & 935 & 1038 & 4.37 & 0 & 0.009 & 10286 & 1 & 1 & 1.20 \\
\hline & \begin{tabular}{|l|} 
NG-5000 \\
\end{tabular} & 5000 & 20 & 695 & 890 & 967 & 3.45 & 0 & 0.008 & 9730 & 1 & 1 & 1.22 \\
\hline \multirow[t]{4}{*}{ Photovoltaics } & PV-010 & 10 & 30 & 8740 & & & & 12 & 0 & & 0 & 1 & \\
\hline & \begin{tabular}{|l|}
$\mathrm{PV}-025$ \\
\end{tabular} & 25 & 30 & 8140 & & & & 12 & 0 & & 0 & 1 & \\
\hline & PV-050 & 50 & 30 & 7940 & & & & 12 & 0 & & 0 & 1 & \\
\hline & \begin{tabular}{|l|}
$\mathrm{PV}-100$ \\
\end{tabular} & 100 & 30 & 7840 & & & & 12 & 0 & & 0 & 1 & \\
\hline
\end{tabular}

source: Firestone, January 2004.

The following is a description of the parameters characterizing each technology in DERCAM.

\section{D1.1 Rated Capacity (maxp)}

$\operatorname{Maxp}$ is the rated maximum electrical output $(\mathrm{kW})$ of the equipment.

\footnotetext{
${ }^{11}$ Source: Firestone, Ryan, DER-CAM Technology Data, January 2004 for complete description of technology parameters.
} 


\section{D.1.2 Lifetime}

Lifetime is the lifetime (in years) of the equipment. No distinction is made between equipment life and financial life. The capital cost of the technology is converted to an annual annuity spread over the lifetime of the equipment. All other cost and performance characteristics are assumed constant over this period.

\section{D.1.3 Capital Costs (Capcost)}

Capcost include the costs of equipment, system design, delivery, and installation. This is a turnkey cost representation. When appropriate, generation equipment can be purchased

- without heat recovery capabilities,

- with heat recovery for heating only,

- with heat recovery for both heating and absorption cooling. ${ }^{12}$

Capcost is expressed as the cost per $\mathrm{kW}$ of rated electrical capacity $(\$ / \mathrm{kW})$.

\section{D.1.4 Operation and Maintenance Fixed Costs (OMFix)}

OMFix includes all fixed annual operation and maintenance costs $(\$ / \mathrm{kW} / \mathrm{a})$ of the equipment, excluding fuel costs.

\section{D.1.5 Operation and Maintenance Variable Costs (OMVar)}

OMVar includes all variable operation and maintenance costs $(\$ / \mathrm{kWh})$ of the equipment, excluding fuel costs, of the equipment.

\section{D.1.6 Heat Rate (HeatR)}

HeatR is the heat rate $(\mathrm{kJ}$ fuel $/ \mathrm{kWh})$, which is related to electrical efficiency, $\mu_{\mathrm{e}}$, by Equation 1).

$$
\text { HeatR }=\frac{3600 \mathrm{~kJ} / \mathrm{kWh}}{\mu_{e}}
$$

HeatR is specified in DER-CAM using the higher heating value (HHV) of natural gas, which is consistent with the purchase price of natural gas. Manufacturers often use the lower heating value (LHV) of natural gas when calculating the heat rate and efficiency for technology specifications. ${ }^{13}$

\footnotetext{
${ }^{12}$ Absorption cooling requires the same heat exchanger for producing hot water (to drive the chiller) as heat recovery for heating requires. Therefore, a system capable of utilizing recovered heat for absorption cooling is also capable of utilizing recovered heat for heating.

${ }^{13}$ An average value for the HHV of natural gas is $38.3 \mathrm{MJ} / \mathrm{m}^{3}$ while for the LHV it is $34.6 \mathrm{MJ} / \mathrm{m}^{3}$ (ORNL, (1)). Thus, the ratio of LHV to HHV is 0.903 . An electrical efficiency for the LHV of natural gas can be multiplied by this ratio to determine the efficiency for the HHV of natural gas.
} 


\section{D.1.7 Heat to Power Ratio $(\alpha)$}

$\boldsymbol{\alpha}$ is the amount of recoverable heat (in $\mathrm{kW}$ ) produced per unit $\mathrm{kW}$ of electricity generated.

In DER-CAM, $\alpha$ is based on the waste heat energy content output from a generator prior to conversion in a heat exchanger. This recoverable heat must then be passed through a heat exchanger to produce useful heat. Heat exchangers are assumed to have an effectiveness of 0.8 (useful $\mathrm{kW}$ heat output / recoverable $\mathrm{kW}$ heat input).

\section{D.2 Other Input Parameters}

\section{D.2.1 DER-CAM parameters}

The following sections describe some of the parameters used in DER-CAM to characterize the heat flow between DER technologies and the end-use loads.

\section{D.2.2 Conversion Efficiency for Recoverable Heat to Load Displacement $(\gamma)$}

$\gamma$ is an estimate of the portion of recoverable heat useful for displacing heating loads through heat exchangers or cooling loads using absorption chillers. $\gamma$ for hot water and space heating loads is the heat exchanger effectiveness. DER-CAM currently assumes a value of 0.8 for $\gamma$ for heat loads.

Cooling loads in DER-CAM are defined as the amount of electricity required to provide the desired level of cooling, assuming a specified value for electric chiller efficiency. $\gamma$ for absorption cooling is, therefore, the ratio of electrical cooling load displacement to recoverable heat. This value must incorporate heat exchanger effectiveness as well as the relative performance of electric and absorption chillers as described in Equation 4, where $\mathrm{COP}_{\mathrm{abs}}$ is the coefficient of performance (COP) ${ }^{14}$ of an absorption chiller and $\mathrm{COP}_{\text {electric }}$ is the coefficient of performance of an electric chiller. COP is defined below.

$$
\begin{array}{ll}
\mathrm{COP}=\mathrm{kW} \text { cooling out } / \mathrm{kW} \text { electricity in } & \text { Equation } 3 \\
\gamma_{a b s}=\text { Effectiveness }_{\text {HeatEx }} * \frac{C O P_{a b s}}{C O P_{\text {electric }}} & \text { Equation } 4
\end{array}
$$

\footnotetext{
${ }^{14}$ The coefficient of performance (COP) of a chiller is the ratio of heat removed by the cooling system to energy (electricity or heat) provided to the cooling system.
} 
$\mathrm{COP}_{\mathrm{abs}}$ has an assumed value of 0.65 for single-stage hot-water fired absorption chillers and $\mathrm{COP}_{\text {electric }}$ has an assumed value of 4 for electric compression driven chillers. ${ }^{15}$ Thus, $\gamma_{\mathrm{abs}}$ has a value of 0.13 for CHP absorption chillers.

\section{D.2.3 Conversion Efficiency for Recoverable Heat to Refrigeration Load Displacement $(\gamma)$}

Refrigeration has separate estimates of heat flow and space cooling parameters and, therefore, another value of $\gamma$ is derived.

This derivation of $\gamma$ is based on studies done by Richard Sweetser, President of Exergy Partners Corp. and Hugh Henderson of CDH Energy. ${ }^{16}$ To these researchers' knowledge, it is the single existing absorption refrigeration system in a grocery store in the United States and is located at a HEB store in southern Texas.

\begin{tabular}{|c|c|}
\hline $80 \mathrm{~kW}$ & Bowman microturbine \\
\hline $683,280 \mathrm{kWh}$ & Electric generation per year \\
\hline $97.5 \%$ & Availability \\
\hline $\begin{array}{l}534,000 \mathrm{kWh} \text { thermal } \\
(152,000 \text { tons }) \text { cooling }\end{array}$ & Cooling production per year by absorption cooling system \\
\hline $1.4 \mathrm{~kW} /$ ton & $\begin{array}{l}\text { Electric load displacement for ton of cooling (average of } \\
\text { medium and low temperature shelves) }\end{array}$ \\
\hline $212,800 \mathrm{kWh}$ & $\begin{array}{l}\text { Electricity reduction for refrigeration loads (savings) per } \\
\text { year }\end{array}$ \\
\hline
\end{tabular}

The electric load displacement converts to an average COP of $2.51(\mathrm{~kW}$ out / $\mathrm{kW}$ in) where $3.516 \mathrm{~kW}$ equals one ton cooling.

Assume $\alpha$ is 2.0 for this $80 \mathrm{~kW}$ engine.

Assume $\gamma$ is 0.8 for a heat exchanger to convert recoverable heat to useful heat input for an absorption cooling unit.

Given $683,280 \mathrm{kWh}$ electric produced per year and 534,000 kWh cooling produced per year,

Then

$683,280 \mathrm{kWh}$ electric produces

$683,280 \times 2.0=1,366,560 \mathrm{kWh}$ thermal

\footnotetext{
${ }^{15}$ DER-CAM assumes that sites have electric chillers installed prior to DER considerations, and a COP of 4 is an approximation of chiller performance for units currently installed in the United States. Actual COPs of electric chillers can vary widely by product and conditions of use such as temperature differential between hot inlet and cold outlet.

${ }^{16}$ Richard Sweetser. Use of a Cooling, Heating, and Power System in a Supermarket. Presentation at Microturbine Conference in Los Angeles, January 2004 and personal communication July 2004.
} 
This $1,366,560 \mathrm{kWh}$ thermal per year produces $534,000 \mathrm{kWh}$ thermal cooling. $1,366,560 \times 0.8=1,093,248 \mathrm{kWh}$ thermal input to absorption cooler per year Then

$$
\mathrm{COP}=534,000 / 1,093,248=0.5 \text { of absorption cooling for refrigeration }
$$

Using equation 4

$\gamma_{\mathrm{abs}}$ for absorption refrigeration with $\mathrm{COP}_{\mathrm{abs}}=0.5$ and $\mathrm{COP}_{\text {electric }}=2.5$ and $\gamma$ is 0.8

$$
\gamma_{\mathrm{abs}}=0.16
$$

This value of $\gamma_{\mathrm{abs}}=0.16$ will be used in the model for using recoverable heat to meet refrigeration loads.

\section{D.2.4 Conversion Efficiency for Fuel to Load Displacement ( $\beta)$}

$\beta$ is an estimate of the amount of available heat output $(\mathrm{kW})$ per unit $(\mathrm{kW})$ of purchased fuel input, in this case natural gas, to displace heat loads with heat exchangers or cooling loads by absorption chillers. For heat loads, this is the boiler efficiency. DER-CAM currently assumes a value of 0.8 for $\beta$ for heat loads and 0 or 0.13 for space cooling loads. The different cooling load values depend on whether natural gas can be burned to supply booster heat to the hot water supply of an indirect fired absorption chiller.

The $\beta$ value for cooling loads is lower than the value for heating loads because DERCAM expresses cooling loads as the amount of electricity needed to provide the desired amount of cooling, and cooling load is invariably expressed as electricity used by an air conditioning system. Thus, $\beta$ for absorption chillers must incorporate the ratio of useful heat out to fuel energy in as well as the relative performance of electric and absorption chillers, as discussed in Section D.2.4. It is assumed that direct natural gas combustion can be used to supplement recovered heat in supplying the heat load to the absorption chiller. Because the heat exchanger effectiveness and boiler efficiency both have an assumed value of $0.8, \beta$ and $\gamma$ have the same values.

\section{D.2.5 $\beta$ and $\gamma$ Values}

Table A- 3 presents the underlying assumptions used to generate $\beta$ and $\gamma$ values for DERCAM. Table A- 4 presents the $\beta$ and $\gamma$ values used. 
Table A- 3: Underlying Assumptions Used For $\beta$ and $\gamma$ Values

Underlying Assumptions

\begin{tabular}{|l|r|}
\hline Heat Exchanger Effectiveness & 0.8 \\
\hline Boiler Efficiency & 0.8 \\
\hline COP, absorption chiller & 0.65 \\
\hline COP, electric chiller & 4 \\
\hline
\end{tabular}

Table A- 4: $\beta$ and $\gamma$ Definitions

\begin{tabular}{|c|c|c|c|c|}
\hline Dd-uce & beta & value & gamma & value \\
\hline electricity-only & $\beta_{\text {electric }}=0$ & 0 & $\gamma_{\text {electric }}=0$ & 0 \\
\hline cooling & $\beta_{a b s}=$ Efficiency $_{\text {boiler }} * \frac{C O P_{a b s}}{C O P_{\text {electric }}}$ & 0.13 & $\gamma_{a b s}=$ Effectiven ess ${ }_{\text {HeatEx }} * \frac{C O P_{\text {abs }}}{C O P_{\text {electric }}}$ & 0.13 \\
\hline space-heating & $\beta_{\text {heating }}=$ Efficiency $_{\text {boiler }}$ & 0.8 & $\gamma_{\text {heating }}=$ Effectiven ess ${ }_{\text {HeatEx }}$ & 0.8 \\
\hline water-heating & $\beta_{\text {heating }}=$ Efficiency $_{\text {boiler }}$ & 0.8 & $\gamma_{\text {heating }}=$ Effectiven ess $S_{\text {HeatEx }}$ & 0.8 \\
\hline naturalgas-only & $\beta_{\text {naturalGas }}=1$ & 1 & $\gamma_{\text {naturalGas }}=0$ & 0 \\
\hline
\end{tabular}




\section{Appendix E. Sensitivity Analyses}

\section{E.1 Parameters in the Core Model}

Interest rate

Lifetimes

Capital cost

O\&M cost

Tariff

Energy charge $(\$ / \mathrm{kWh})$

Demand charge

Standby charge

Gas prices

Absorption refrigeration

Technologies

Beta

Load

Technology
$5 \%$ for separate refrigeration load model

$7.5 \%$ for integrated refrigeration load model

20 years

1 includes CPUC subsidies for heat recovery

1 includes departing load charge of $\$ 0.0382 / \mathrm{kWh}$

DA and SCE

1 current tariff rate

1 current tariff rate

1 (\$0.44 and $\$ 1.00$ for DA and SCE respectively)

$1(\$ 6.057 \mathrm{E}-06 / \mathrm{kJ})$

yes (six end-use loads)

All natural gas engines $<=500 \mathrm{~kW}$ for non refrigeration Limited set of technologies for refrigeration load model Minimum power output is $50 \%$ of full load, else shutdown PV 50kW and $100 \mathrm{~kW}$, no minimum power output 0 no direct fired absorption cooling with and without refrigeration end-use loads added $500 \mathrm{~kW} \mathrm{NG}$ engine to model in three forms

\section{E.1.1 Sensitivity Analysis Range of Parameters}

Direct Access (DA) tariff

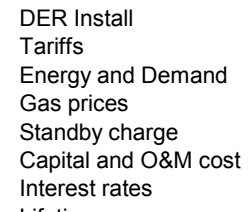

Interest rates

Lifetime

$\begin{array}{rr}0.7 & 0.75 \\ 0.75 & 0.9 \\ 2 & 4 \\ 1 & 1.1 \\ 0.05 & 0.075 \\ 10 & 15\end{array}$

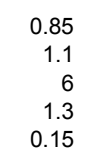

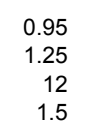

$\begin{array}{rrr}1.2 & 1.3 & 1.5 \\ 1.5 & 2 & \\ 20 & & \\ 1.8 & 1.9 & 2\end{array}$

3 



\section{Appendix F. CPUC Self-generation Incentive Program ${ }^{17}, 18$}

After passage of California Assembly Bill 970 in September 2000, the CPUC approved a statewide self-generation incentive program, which provides financial incentives to customers who install new qualifying self-generation equipment up to $1.5 \mathrm{MW}$ system size to provide all or a portion of their electrical needs. The program is administered by Pacific Gas and Electric (PG\&E), Southern California Edison (SCE), Southern California Gas Company (SoCalGas) and the San Diego Regional Energy Office (SDREO, serving SDG\&E customers), and provides \$125 million annually statewide.

Table A- 5: Technologies Eligible for CPUC Self-Generation Rebates ${ }^{19}$

\begin{tabular}{|c|c|c|c|c|c|}
\hline $\begin{array}{c}\text { Incentive } \\
\text { Category }\end{array}$ & $\begin{array}{c}\text { Incentive } \\
\text { Offered }\end{array}$ & $\begin{array}{c}\text { Maximum } \\
\text { \% of } \\
\text { Project } \\
\text { Cost }\end{array}$ & $\begin{array}{c}\text { Minimum } \\
\text { System Size }\end{array}$ & $\begin{array}{c}\text { Maximum } \\
\text { System } \\
\text { Size* }\end{array}$ & $\begin{array}{c}\text { Eligible } \\
\text { Technologies }\end{array}$ \\
\hline Level 1 & $\$ 4500 / \mathrm{kW}$ & $50 \%$ & $30 \mathrm{~kW}$ & $1.5 \mathrm{MW}$ & $\begin{array}{l}\text { photovoltaics, fuel cells } \\
\text { operating on renewable } \\
\text { fuel, and wind turbines }\end{array}$ \\
\hline Level 2 & $\$ 2500 / \mathrm{kW}$ & $40 \%$ & None & $1.5 \mathrm{MW}$ & $\begin{array}{l}\text { fuel cells operating on } \\
\text { non-renewable fuel and } \\
\text { utilizing sufficient } \\
\text { waste heat recovery }\end{array}$ \\
\hline $\begin{array}{c}\text { Level 3-R } \\
\text { Renew- } \\
\text { able }\end{array}$ & $\$ 1500 / \mathrm{kW}$ & $40 \%$ & None & $1.5 \mathrm{MW}$ & $\begin{array}{l}\text { microturbines, small } \\
\text { gas turbines, internal } \\
\text { combustion engines, } \\
\text { operating on renewable } \\
\text { fuel }\end{array}$ \\
\hline $\begin{array}{c}\text { Level 3-N } \\
\text { Non- } \\
\text { renew- } \\
\text { able }\end{array}$ & $\$ 1000 / \mathrm{kW}$ & $30 \%$ & None & $1.5 \mathrm{MW}$ & $\begin{array}{l}\text { microturbines, small } \\
\text { gas turbines, internal } \\
\text { combustion engines, } \\
\text { using sufficient waste } \\
\text { heat recovery and } \\
\text { meeting reliability } \\
\text { criteria }\end{array}$ \\
\hline
\end{tabular}

For program purposes, self-generation refers to "clean distributed generation technologies," such as microturbines, fuel cells, photovoltaic, small gas turbines, wind turbines, and internal combustion engines, that meet the following criteria:

\footnotetext{
${ }^{17}$ CPUC Self-Generation Incentive Program July-December 2001 Status Report, referenced May 2004, http://www.cpuc.ca.gov/published/report/13690.htm

${ }^{18}$ San Diego Regional Energy Office, San Diego SELFGEN, May 2004, http://www.sdge.com/business/self_generation.shtml

${ }^{19}$ San Diego Regional Energy Office, San Diego SELFGEN Program, May 2004, http://www.sdge.com/business/incentive_programs.shtml\#self
} 
- At least 5\% of the power system's total energy output is in the form of useful thermal energy.

- Where useful thermal energy results from power production, the useful annual electrical output plus one-half the annual useful thermal energy output equals not less than $42.5 \%$ of any natural gas and oil energy input.

- In the case of microturbines, small gas turbines, and internal combustion engines, the following power quality and reliability requirements must be met:

- The self-generating facility must be designed to operate in power factor mode such that the generator operates between 0.95 power factor loading and 0.90 power factor leading.

- Sites with greater than $200 \mathrm{~kW}$ generating capability must coordinate maintenance schedules with the local utility, and in general can only schedule maintenance from October to March, and if necessary only during off peak or weekend hours between April and September.

The funding from this program is available as a secondary source after other sources have been fully tapped. The CPUC funding limits are decreased by the amount of alternate funding. In other words, the limits set out by the CPUC represent a cap to funding available to qualifying sites in California. It is assumed, therefore, that the test sites located in California that indicated they are applying for or have received CPUC self-generation funding are qualifying facilities, and will receive funding up to the limits set by the CPUC in this program. 


\section{Appendix G. Load Profiles}

\section{G.1 Load Profiles}

Ideally, complete electric and thermal load profiles on an hourly basis for a full year (historical, or even better, forecast) would be available as input to DER-CAM. At NBVC, however, the load data consisted of four years of monthly electric and gas meter readings (November 1998 to January 2004) for both the Commissary and NEX. The period between September 2001 and July 2002 was excluded because the data was incomplete (the missing information was obtained for the Commissary but not for the NEX). The remaining monthly electric and natural gas data were averaged to obtain baseline monthly electric and natural gas consumption.

The DOE-2 building energy simulator was used to estimate missing data for hourly electricity, heating, and cooling loads. A simplified user interface was developed for DER-CAM modeling, from which to generate hourly load estimates based on building type, location, interior area, and known information about the building's energy consumption. Output data were generated as hourly reports containing selected DOE-2 output specifications.

The DOE-2 model was used to develop load profiles for the following building types: a retail store (NEX), a supermarket (Commissary), and a fast food restaurant (the food court). The output was added to find the loads for each major component of Building 1512 and then scaled to match the data.

The DER-CAM load input is a matrix containing average hourly load data by weekday and weekend for the twelve months of the year. Thus, there are 24 rows of data per load type. There are six end-use load types, giving a total of 144 rows of load data, with 24 columns. The six DER-CAM load types used in this study are:

- electricity-only: loads met only by electricity and that cannot be met by natural gas or CHP heat (lighting, computing, etc.),

- space cooling: loads met by electricity or heat recovery through absorption chillers,

- refrigeration: loads met by electricity or heat recovery through absorption chillers,

- space heating: loads met either directly by natural gas or with residual heat from CHP,

- water heating: loads met either directly by natural gas or with residual heat from CHP,

- natural-gas-only: loads met only by natural gas and with no CHP opportunities (primarily cooking).

DOE-2 output was converted to appropriate SI (Standard International) units, and then each load profile was added to one of the five end-use load types. This involved estimation of the type of energy system DOE-2 modeled during the load profile generation.

A Visual Basic for Applications macro was built in Microsoft Excel to convert the DOE-2 output into the format needed by DER-CAM. An hour-by-hour load profile for each month was computed from hourly load profiles for each day of the year (8760 hours total), end use, and day type by averaging all the values of each particular hour, month, end use, and day type. This 
macro also recorded the peak hourly load for each month and each day type, and used that peak day to develop a "peak day" load shape for each month and load type.

These load profiles were displayed in a spreadsheet and adjusted to match historic metered data provided by Public Works regarding the energy use of Building 1512 from November 1998 to January 2004. Sensitivity analyses were performed on two separate models of Building 1512: a model including refrigeration loads as a separate end use that can be served with absorption cooling (the separate refrigeration model) and a model where the refrigeration loads are part of the site's electricity-only load (the integrated refrigeration model).

For the separate refrigeration load model, a flat refrigeration load was created by breaking out a portion of the electricity-only load. This process is described in further detail in Appendix G. The electricity-only load from DOE- 2 was multiplied by 0.8 and cooling load by 0.5 to match these loads, in addition to the refrigeration load, with the monthly billing data.

For the integrated refrigeration model, the electricity-only and cooling loads from DOE-2 were multiplied by 0.96 to approximate the average loads provided by historic meter readings. The space heating, water heating, and natural-gas-only loads from DOE-2 were multiplied by 0.85 .

The refrigeration load was estimated by assuming Building 1512 (both the Commissary and NEX) loads were equivalent to an average refrigeration load in a supermarket. A supermarket's average connected load is generally estimated to be $440 \mathrm{~kW}$, with refrigeration equipment using $55 \%-57 \%$, or about $245 \mathrm{~kW} .{ }^{20}$ The duty cycle of refrigeration compressors averages $85 \%$ for low temperature and $55 \%$ for medium temperature. In this analysis, the duty cycle was assumed to be $50 \%$ of the connected refrigeration load, about $123 \mathrm{~kW}$ each hour of the year. ${ }^{21}$ The electricity-only and space-cooling loads were adjusted accordingly to bring the model loads in line with the metered data.

The following figures show the load profiles for Building 1512.

${ }^{20}$ A.D. Little, March 2002. Section 8 Commercial Refrigeration. http://www.arap.org/adlittle/8.html

${ }^{21}$ Average load assumed to be half of connected load as a result of discussions with Steve Greenberg, July 2004 


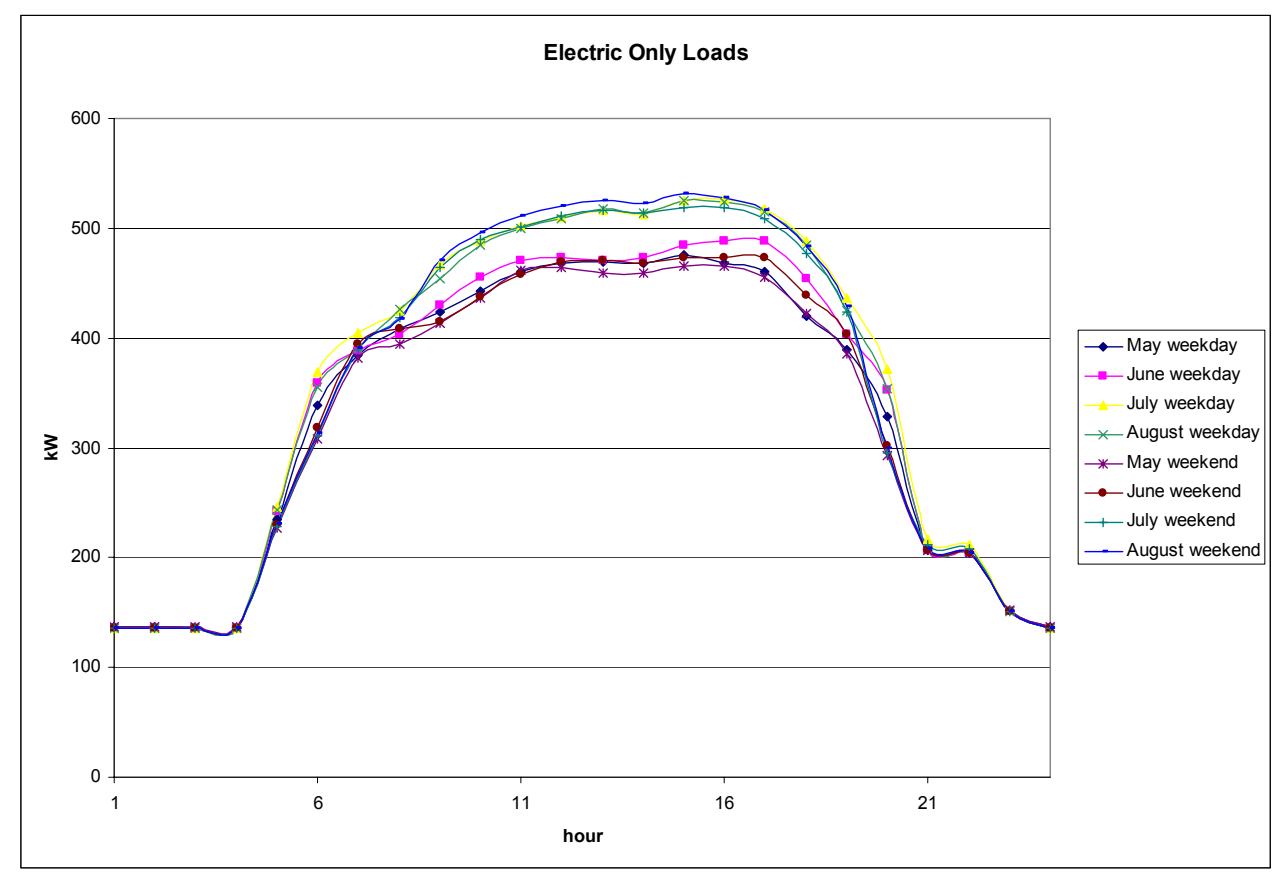

Figure A- 1: Electric Only Load Profile for Building 1512

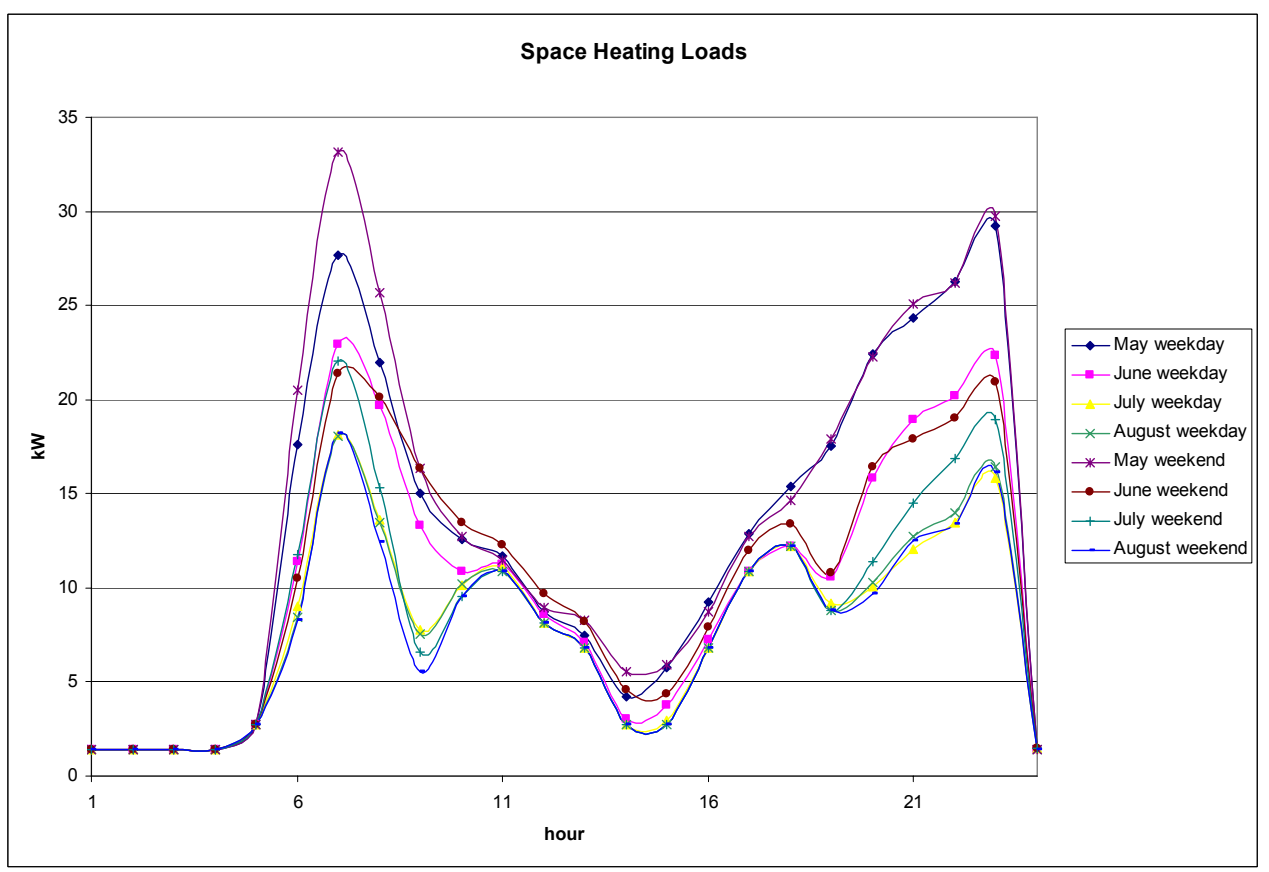

Figure A- 2: Space Heating Only Load Profile for Building 1512 
Distributed Energy Resources at Naval Base Ventura Country Building 1512

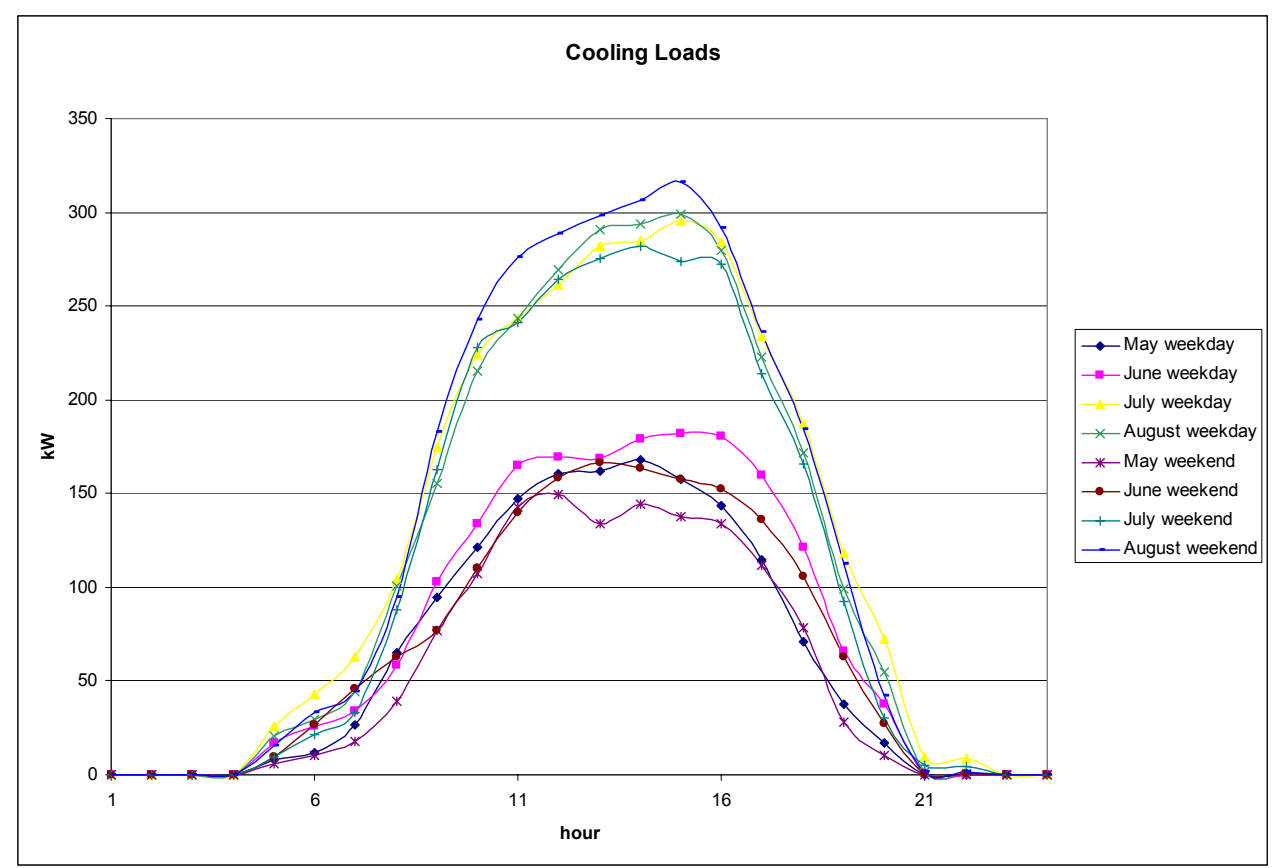

Figure A- 3: Cooling Only Load Profiles for Building 1512 


\section{Appendix H. Tariff Information}

\section{H.1 Summary of NBVC Tariff}

\section{H.1.1 Direct Access}

NBVC has a direct access contract with an energy service provider, Strategic Energy, and electricity delivery services are through SCE under tariff TOU-8 direct access. The Strategic Energy contract is effective through March 2005 and it is renewable indefinitely. ${ }^{22}$ Natural gas is also purchased from a direct supplier and SoCalGas charges for delivery. The net tariff estimated by combining the Strategic Energy charge and the SCE TOU-8 direct access charge is here called the direct access tariff.

In summary, NBVC tariffs currently have the following components:

- Strategic Energy: direct access supplier and

- SCE consisting of the following components:

- Schedule TOU-8,

- Schedule DA-CRS: Direct Access Cost Responsibility Surcharge,

- Schedule DL-NBC: Departing Load Nonbypassable Charges,

- Schedule S Standby.

Table A-6 shows the actual tariffs NBVC is charged by adding Strategic Energy's rates for electricity generation and SCE's delivery service rates under the direct access tariff. These prices are calculated using June 2004 bills and assume the direct access prices will remain constant. Figure A-4 below shows the commodity prices for electricity charged by Strategic Energy. The direct access cost responsibility surcharge (DA-CRS) consists of $\$ 0.00493 / \mathrm{kWh}$ for the DWR Bond Charge, $\$ 0.01 / \mathrm{kWh}$ for the historic procurement charge (HPC) to recover direct access customers' share of SCE's Procurement Related Obligations Account, and the residual $\$ 0.01207 / \mathrm{kWh}$ is applied to the DWR 2004 Power Charge. ${ }^{23}$

\footnotetext{
${ }^{22}$ Veronica Jarvis, Strategic Energy, personal communication, March 2004.
}

${ }^{23}$ SCE's Schedule DA-CRS, Filed Jan 22, 2004, effective Feb 1, 2004. 
Table A- 6: Direct Access Tariff Components at NBVC

\begin{tabular}{|l|l|l|l|l|l|}
\hline & $\begin{array}{l}\text { Strategic } \\
\text { energy } \\
\mathbf{( \$ / k W h )}\end{array}$ & $\begin{array}{l}\text { SCE TOU-8 } \\
\text { Direct Access } \\
\text { Delivery } \\
\text { Service } \\
\mathbf{( \$ / k W h )}\end{array}$ & $\begin{array}{l}\text { SCE TOU-8 } \\
\text { HPC, DWR } \\
\text { Power and } \\
\text { Bond } \\
\text { charges }\end{array}$ & $\begin{array}{l}\text { Total Tariff } \\
\text { TOU rate } \\
\mathbf{( \$ / k W h )}\end{array}$ & $\begin{array}{l}\text { Total } \\
\text { Demand } \\
\text { Charges } \\
\mathbf{\$} / \mathbf{k W}\end{array}$ \\
\hline $\begin{array}{l}\text { On Peak } \\
\text { Summer }\end{array}$ & 0.0643 & 0.00686 & 0.027 & 0.09816 & 6.91 \\
\hline $\begin{array}{l}\text { Mid Peak } \\
\text { Summer }\end{array}$ & 0.0643 & 0.00686 & 0.027 & 0.09816 & 0.46 \\
\hline $\begin{array}{l}\text { Off Peak } \\
\text { Summer }\end{array}$ & 0.0643 & 0.00686 & 0.027 & 0.09816 & 0 \\
\hline $\begin{array}{l}\text { On Peak } \\
\text { Winter }\end{array}$ & 0.0643 & 0.00686 & 0.027 & 0.09816 & 1.61 \\
\hline $\begin{array}{l}\text { Mid Peak } \\
\text { Winter }\end{array}$ & 0.0643 & 0.00686 & 0.027 & 0.09816 & 0 \\
\hline $\begin{array}{l}\text { Off Peak } \\
\text { Winter }\end{array}$ & 0.0643 & 0.00686 & 0.027 & 0.09816 & 0 \\
\hline
\end{tabular}

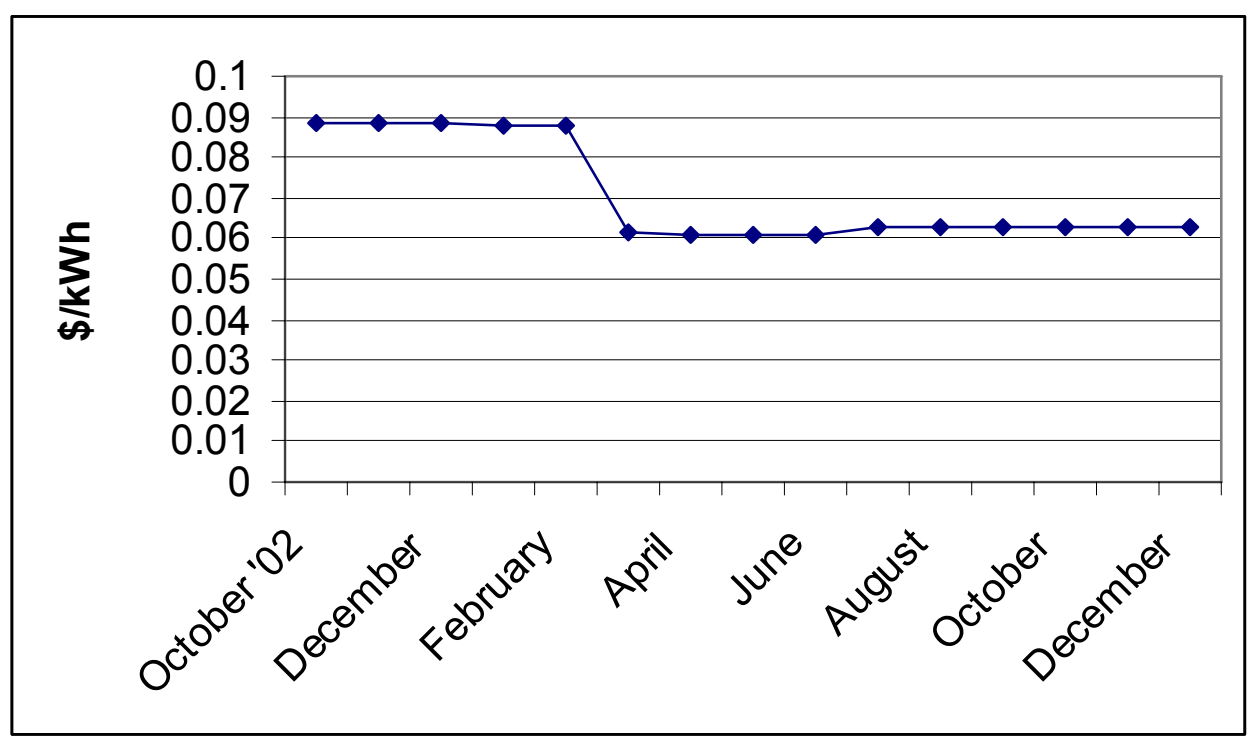

Figure A- 4: Direct Access Energy Supply Prices by Strategic Energy 


\section{Other direct access tariff characteristics}

Customer charge (\$/meter/month): $\quad 224.22$

Facility charge $(\$ / \mathrm{kW} / \mathrm{month}) \quad 1.51$

Power Factor Adjustment ( $\$ / \mathrm{KVA} /$ month) $\quad 0.1028$

Assume reactive power near zero so it is $\$ / \mathrm{kW} /$ month)

Total Facility charge (\$/kW/month) $\quad 1.6128$

Time dependent demand charges $(\$ / \mathrm{kW} /$ month $)$

On-peak summer:

Mid-peak summer

Else:

Standby charge $(\$ / \mathrm{kW} /$ meter/month)

With direct access $(\$ / \mathrm{kV} /$ meter/month $)$

Departing load ( $\$$ kWh from DER/month)

$0.00191+0.00191=0.00382$

Add this to O\&M variable cost of each DG unit

Schedule SSGDR Simplified Self Generation Deferral Rate: not applicable ${ }^{24}$

\footnotetext{
${ }^{24}$ Not applicable for NBVC according to Nathan Smith at SCE. Personal communication on 16 July 2004
} 
Table A- 7 below shows the main components of the direct access and SCE TOU- 8 tariff rates. This tariff was filed January 22, 2004 and effective February 1, 2004. ${ }^{25}$

Table A- 7: SCE Schedule TOU-8, applicable for direct access and SCE TOU-8 tariffs

\section{SERVICE METERED AND DELIVERED AT VOLTAGES ABOVE $50 \mathrm{KV}$}

\begin{tabular}{|c|c|c|c|c|c|c|c|c|c|}
\hline & \multicolumn{7}{|c|}{ Delivery Service } & \multicolumn{2}{|c|}{ Gen $^{\circ}$} \\
\hline & Trans & Distrbtn $^{2}$ & $\mathrm{NDC}^{3}$ & $\mathrm{PPPC}^{4}$ & PUCRF $^{\circ}$ & DWRBC $^{6}$ & Total $^{\prime}$ & URG & DWR \\
\hline \multicolumn{10}{|l|}{ Energy Charge - \$/kWh/Meter/Month } \\
\hline Summer Season - On-Peak & 0.00008 & 0.00449 & 0.00026 & 0.00191 & 0.00012 & $0.00493(1)$ & $0.01179(1)$ & 0.11413 & $0.08918(R)$ \\
\hline Mid-Peak & 0.00008 & 0.00449 & 0.00026 & 0.00191 & 0.00012 & $0.00493(I)$ & 0.01179 (I) & 0.04314 & $0.08918(R)$ \\
\hline Off-Peak & 0.00008 & 0.00449 & 0.00026 & 0.00191 & 0.00012 & $0.00493(1)$ & $0.01179(\mathrm{I})$ & 0.03209 & $0.08918(R)$ \\
\hline Winter Season - On-Peak & N/A & N/A & N/A & N/A & N/A & N/A & N/A & $\mathrm{N} / \mathrm{A}$ & N/A \\
\hline Mid-Peak & 0.00008 & 0.00449 & 0.00026 & 0.00191 & 0.00012 & $0.00493(\mathrm{I})$ & $0.01179(l)$ & 0.05200 & $0.08918(R)$ \\
\hline Off-Peak & 0.00008 & 0.00449 & 0.00026 & 0.00191 & 0.00012 & $0.00493(1)$ & $0.01179(\mathrm{l})$ & 0.03307 & $0.08918(R)$ \\
\hline Customer Charge - \$/Meter/Month & 0.00 & 224.22 & & & & & 224.22 & 125.23 & \\
\hline \multicolumn{10}{|c|}{ Demand Charge- $\$ / \mathrm{kW}$ of Billing Demand/Meter/Month } \\
\hline Facilities Related & 1.25 & 0.26 & & & & & 1.51 & 0.00 & \\
\hline \multicolumn{10}{|l|}{ Time Related } \\
\hline Summer Season - On-Peak & 0.00 & 5.30 & & & & & 5.30 & 8.10 & \\
\hline Mid-Peak & 0.00 & 0.46 & & & & & 0.46 & 1.57 & \\
\hline Off-Peak & 0.00 & 0.00 & & & & & 0.00 & 0.00 & \\
\hline Winter Season - On-Peak & N/A & N/A & & & & & N/A & $\mathrm{N} / \mathrm{A}$ & \\
\hline Mid-Peak & 0.00 & 0.00 & & & & & 0.00 & 0.00 & \\
\hline Off-Peak & 0.00 & 0.00 & & & & & 0.00 & 0.00 & \\
\hline
\end{tabular}

Key:

Trans $=\quad$ Transmission and the Transmission Owners Tariff Charge Adjustments which are FERC approved.

Distrbtn $=$ Distribution

$\mathrm{NDC}=\quad$ Nuclear Decommissioning Charge

PPPC $=\quad$ Public Purpose Programs Charge

PUCRF $=\quad$ The PUC Reimbursement Fee is described in Schedule RF-E

DWRBC $=$ Department of Water Resources (DWR) Bond Charge.

Total $=\quad$ Total Delivery Service rates that are applicable to bundled service and direct access customers

Gen $=\quad$ Generation: the Gen rates are applicable only to Bundled Service Customers. When calculating the Energy Charge, the Gen portion is calculated as described in the Billing Calculation Special Condition of this Schedule.

Special Conditions:

Time periods are defined as follows:

On-peak: $\quad$ Noon to 6:00 pm summer weekdays except holidays

Mid-peak: $\quad$ 8:00 am to Noon and 6:00 pm to 11:00 pm summer weekdays except holidays

8:00 am to 9:00 pm winter weekdays except holidays

Off-peak: $\quad$ All other hours

\footnotetext{
${ }^{25}$ Schedule TOU-8, Time of Use, General Service Large. SCE website July 2004.
} 
The summer season shall commence at 12:00 am on the first Sunday in June and continue until 12:00 am of the first Sunday in October of each year. The winter season shall commence at 12:00 am on the first Sunday in October and continue until 12:00 am of the first Sunday in June of the following year.

\section{H.1.2 Direct supply}

Natural gas is obtained through the Defense Energy Support Center in Fort Belvoir, VA. Prices between September 2002 and August 2003 fluctuated between \$3.16/ GJ (\$3.330/ MBTU) and $\$ 6.63 / \mathrm{GJ}$ (\$6.99/MBTU), so an average price of $\$ 5.11 / \mathrm{GJ}$ (\$5.39/MBTU) was used for these analyses. SoCalGas delivers the gas at a rate that also varies monthly, so it was set at $\$ 0.95 / \mathrm{GJ}$ (\$1.00/MBTU) based on the historic average. The gas rate totals $\$ 6.06 / \mathrm{GJ}$ (\$6.39/MBTU).

Figure A-5 below depicts the commodity prices of natural gas from September 2002 to August 2003 as obtained from the direct supply bills. These costs do not include SoCalGas's transportation charge of $\$ 0.95 / \mathrm{GJ}(\$ 1.00 / \mathrm{MBTU})$.

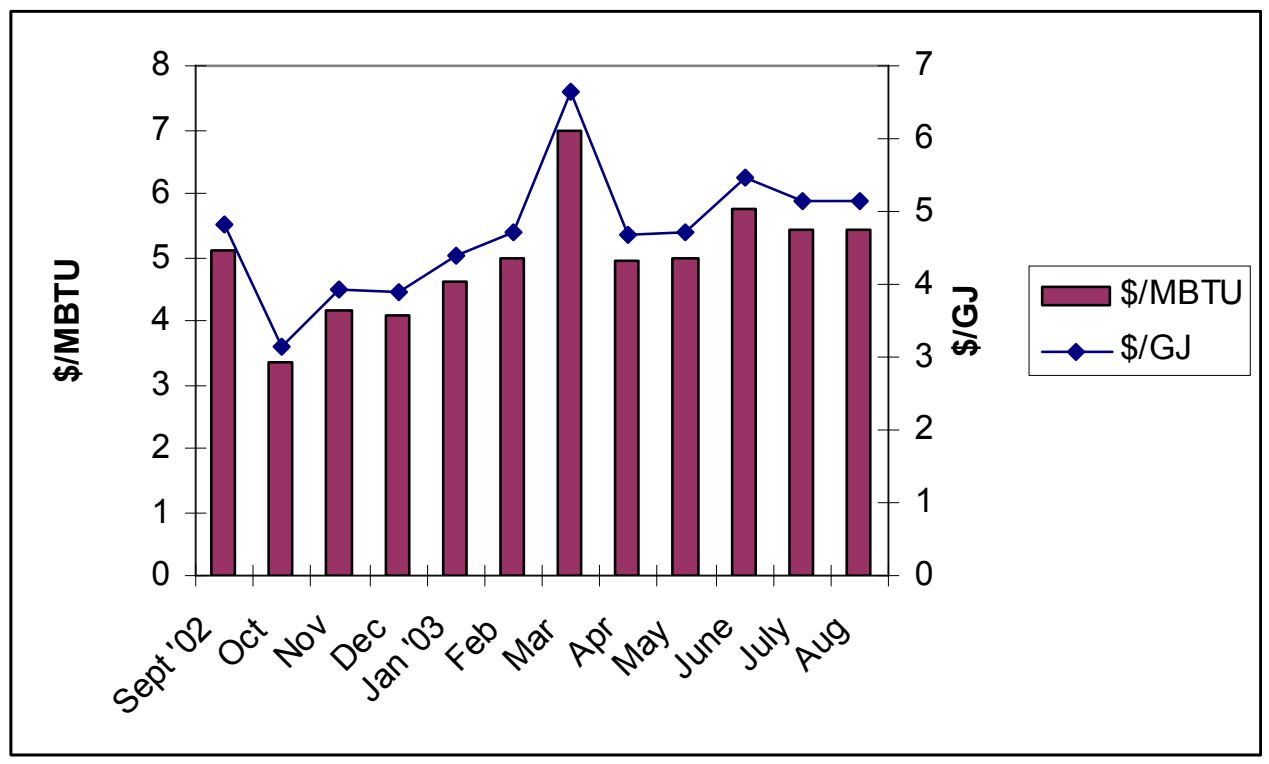

Figure A- 5: NBVC Natural Gas Commodity Prices 2002-2003 